\title{
Fuzzy Logic Based Control of the Lateral Stability of Tractor Semitrailer Vehicle
}

\author{
Xiujian Yang, Juntao Song, and Jin Gao \\ Faculty of Transportation Engineering, Kunming University of Science and Technology, Kunming 650500, China
}

Correspondence should be addressed to Xiujian Yang; yangxiujian2013@163.com

Received 22 July 2015; Revised 6 October 2015; Accepted 7 October 2015

Academic Editor: Muhammad N. Akram

Copyright (C) 2015 Xiujian Yang et al. This is an open access article distributed under the Creative Commons Attribution License, which permits unrestricted use, distribution, and reproduction in any medium, provided the original work is properly cited.

A novel control scheme is proposed to improve the yaw stability of a tractor semitrailer vehicle in critical situations. The control scheme is a two-layer structure consisting of an upper yaw moment controller and a lower brake force distributor. The tractor and the trailer are, respectively, stabilized by two independent fuzzy logic based yaw moment controllers. The controllers for the tractor and the trailer are, respectively, designed to track the reference yaw rate of the tractor and the hitch angle between the tractor and the trailer while considering the variation of the hitch angular rate at the same time. The corrective yaw moments determined by the corresponding upper fuzzy yaw moment controllers are realized by active wheel braking. The performance of the proposed control scheme is evaluated by simulations on a nonlinear vehicle model. The results demonstrate that the proposed control scheme is robust and effective in stabilizing the severe instabilities such as jackknife and trailer oscillation in the chosen simulation scenarios. It is believed that this control scheme is robust to the variation of road adhesion conditions.

\section{Introduction}

Tractor semitrailer as a very common commercial heavy vehicle plays an important role in road transportations in all over the world. However, it is prone to lose lateral stability and cause fatal accidents because of its relative lower stability capability which mainly results from its particular multibody structure and high center of gravity (CG) [1]. Generally, for a typical tractor semitrailer vehicle, rollover caused by high lateral acceleration and loss-of-control (LOC) of planar yaw dynamics such as jackknife and trailer oscillation caused by the tractor or trailer's excess pivoting motion are the primary concerns of lateral stability [2-5]. In fact, the roll stability is closely associated with the yaw dynamics since excess yaw motion generally causes a rollover especially when the CG is relatively high. So, in this paper, we mainly focus on the issue of planar yaw dynamics control thereby preventing the occurrence of rollover.

In critical driving situations, a tractor-trailer may confront different forms of yaw instability such as jackknife, trailer swing, and trailer oscillation depending on the load, configuration characteristic parameters, steer input, and other external disturbances. The schematic of these instabilities are being shown in Figure $1[3,6,7]$. Under situations of braking on slippery road for a tractor-trailer, jackknife often happens at the side slip of the rear wheels of the tractor and trailer swing generally appears at the side slip of the wheels of the trailer while trailer oscillation is primarily related to the characteristic of rearward amplification [8]. Rearward amplification as a typical characteristic for a tractor-trailer vehicle is much related to the vehicle configuration characteristics and load conditions and thereby can cause the trailer to react intensely with a relatively small external disturbance in lateral direction added to the tractor or the trailer. In fact, it is difficult to clearly distinguish jackknife and trailer swing since they have similar destabilizing mechanism that is divergence from the perspective of stability theory of the dynamical system. However, trailer oscillation which is very different is generally referred to as oscillatory instability [7]. Particularly, these phenomena of LOC can be differentiated and interpreted based on nonlinear dynamics theories such as stability of equilibrium, state flow, and bifurcation [8]. In recent years, the lateral dynamics of the multibody vehicles are still a hot research area in academia $[9,10]$. 
In critical situations, generally, it is difficult for a driver to manipulate a tractor semitrailer vehicle when he recognizes the vehicle being about to lose cornering stability. Fortunately, similar to the passenger cars, the stability of a tractor-trailer combination can also be considerably improved by active control method [7, 11-13]. In recent years, electronic stability control (ESC) systems which have been widely equipped in passenger cars for a few years attract much interest from both the industry and academia in having ESC systems developed for and implemented in the heavy vehicles [1, 14]. ESC system can really assist in improving the safety for a tractor semitrailer by improving the yaw and rollover stabilities [1].

For a typical vehicle dynamics system, there are many uncertainties and nonlinearities such as vehicle configuration parameters, payload, and road adhesion conditions, which have considerable effect on the performance of the vehicle dynamics control system. In this study, in order to improve the stability of a tractor semitrailer vehicle with parametric uncertainties in critical situations, a robust control scheme is proposed based on fuzzy logic control method to stabilize the yaw dynamics of the tractor and the trailer separately and thereby improve the roll stability. Fuzzy logic control method which is described in simple vague linguistic terms and is suitable for the control of nonlinear systems especially with parametric uncertainties has been widely used in vehicle dynamics control systems [15-17].

The rest of the paper is organized as follows. In the following section, a nonlinear tractor semitrailer vehicle model is formulated replacing the real-world vehicle to assess the performance of the proposed control scheme. The detail of the proposed control system is described in Section 3. Simulation results are presented in Section 4 to check and evaluate the effectiveness of the proposed control scheme. Finally, the contributions and conclusions are summarized in Section 5. The notations referred to in figures and equations and vehicle parameters used in simulation are listed and described in Appendices A and B.

\section{Nonlinear Tractor Semitrailer Vehicle Model}

In this section, nonlinear models including the motions of the body, suspension, and tyre of a tractor semitrailer vehicle are formulated to replace the real-world vehicle for simulation to evaluate the performance of the proposed control scheme.

The nonlinear schematic model for a typical tractor semitrailer vehicle is shown in Figure 2 which describes the vehicle configuration, forces applied on it, and the kinematics. The dual-tyre of the tractor and trailer in Figure 2 is processed as single-tyre in the following mathematical formulations and also in the design of the brake force distributor in Section 3.4.

2.1. Motion Equations of the Vehicle. Vehicle body model comprises the motions of longitudinal, lateral, yaw, and body roll for both the tractor and trailer and the coupling constraints between them. The pitch motions are not involved and the roll axis is fixed. The equations of these motions can be derived based on Lagrange's approach and the principle of virtual work. The details of formulation will no longer be

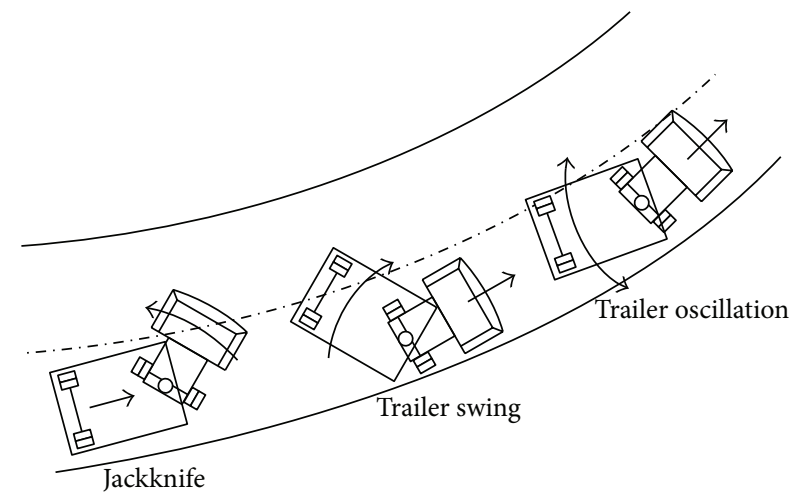

FIGURE 1: Schematic of yaw instabilities of a typical tractor semitrailer vehicle.

presented. As a result, the motions of longitudinal, lateral, yaw, and body roll for the tractor can, respectively, be formulated by the following:

$$
\begin{aligned}
& m_{1}\left(\dot{v}_{x 1}-\gamma_{1} v_{y 1}\right)\left(F_{x 1}+F_{x 2}\right) \cos \delta_{f}+F_{x 3}+F_{x 4} \\
&-\left(F_{y 1}+F_{y 2}\right) \sin \delta_{f}+F_{h x}, \\
& m_{1}\left(\dot{v}_{y 1}+\gamma_{1} v_{x 1}\right)+m_{1 s} h_{s 1} \ddot{\phi}_{1} \\
&=\left(F_{y 1}+F_{y 2}\right) \cos \delta_{f}+F_{y 3}+F_{y 4} \\
& \quad+\left(F_{x 1}+F_{x 2}\right) \sin \delta_{f}-F_{h y}, \\
& I_{z 1} \dot{\gamma}_{1} \quad \\
&=\left(F_{y 1}-F_{y 2}\right) \frac{t_{w 1}}{2} \sin \delta_{f}+\left(F_{x 2}-F_{x 1}\right) \frac{t_{w 1}}{2} \cos \delta_{f} \\
& \quad+\left(F_{y 1}+F_{y 2}\right) a_{1} \cos \delta_{f}+\left(F_{x 1}+F_{x 2}\right) a_{1} \sin \delta_{f} \\
& \quad-\left(F_{y 3}+F_{y 4}\right) b_{1}+\left(F_{x 4}-F_{x 3}\right) \frac{t_{w 2}}{2}+F_{h y} l_{p}, \\
& I_{x 1}
\end{aligned}
$$

Similarly, the motions of longitudinal, lateral, yaw, and body roll motions for the trailer can, respectively, be modeled as the following:

$$
\begin{aligned}
& m_{2}\left(\dot{v}_{x 2}-\gamma_{2} v_{y 2}\right)=F_{x 5}+F_{x 6}-F_{h x} \cos \theta+F_{h y} \sin \theta, \\
& m_{2}\left(\dot{v}_{y 2}+\gamma_{2} v_{x 2}\right)+m_{2 s} h_{s 2} \ddot{\phi}_{2} \\
& \quad=F_{y 5}+F_{y 6}+F_{h y} \cos \theta-F_{h x} \sin \theta,
\end{aligned}
$$




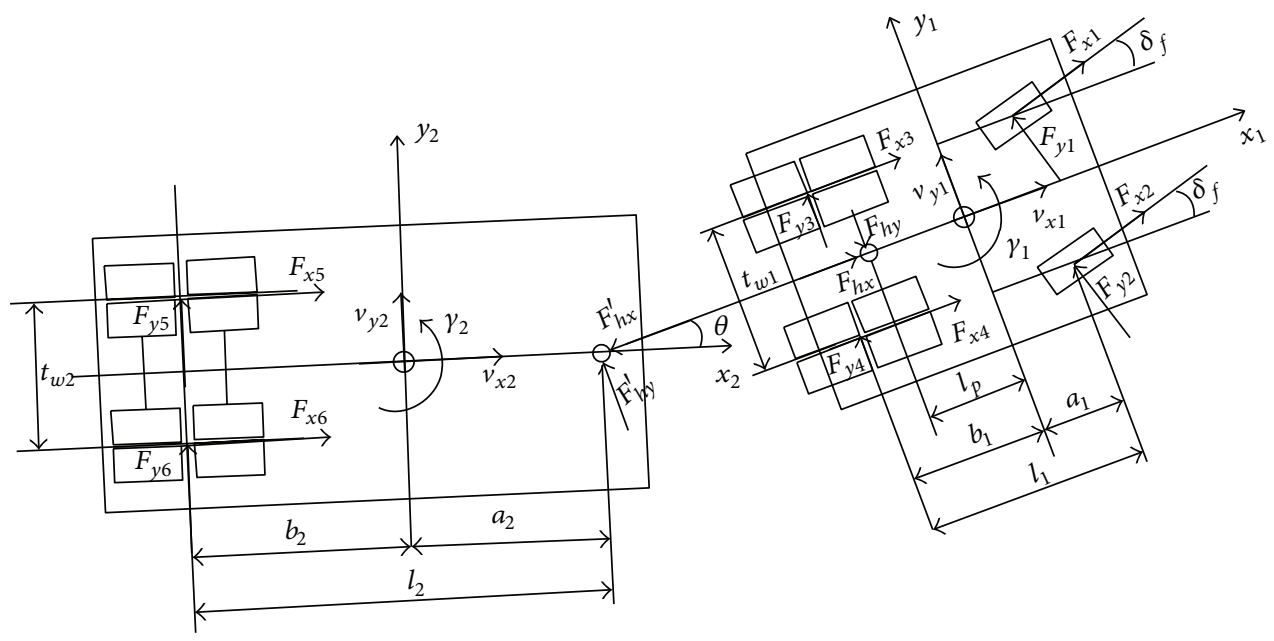

(a)

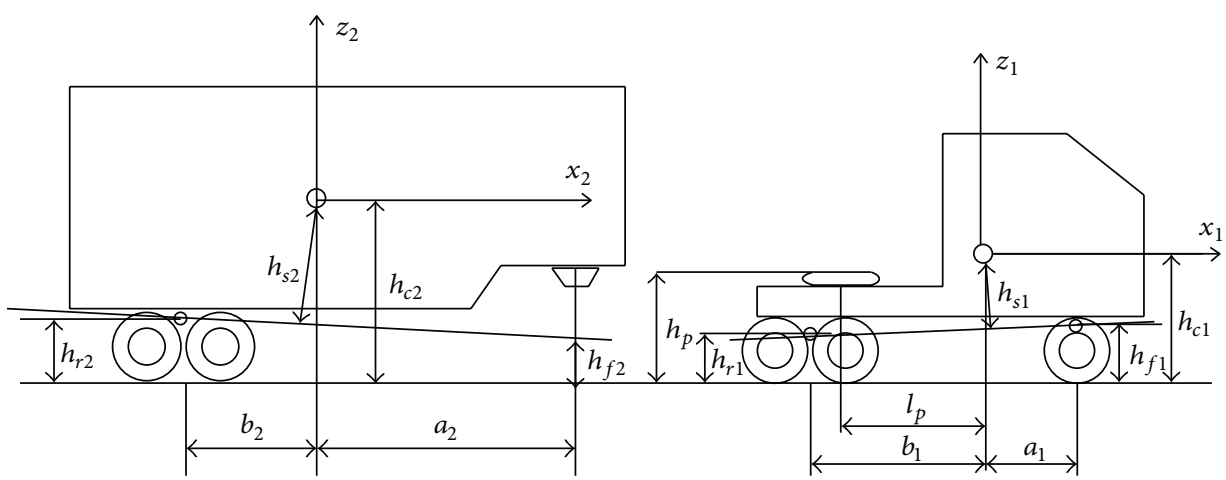

(b)

FIGURE 2: The schematic model of a typical tractor semitrailer vehicle.

$$
\begin{aligned}
I_{z 2} \dot{\gamma}_{2} & \\
= & \left(F_{h y} \cos \theta-F_{h x} \sin \theta\right) a_{2}-\left(F_{y 5}+F_{y 6}\right) b_{2} \\
& +\left(F_{x 6}-F_{x 5}\right) \frac{t_{w 3}}{2}, \\
I_{x 2} \ddot{\phi}_{2} & +m_{2 s}\left(\dot{v}_{y 2}+\gamma_{2} v_{x 2}\right) h_{s 2} \\
= & \left(F_{z 6}-F_{z 5}\right) \frac{t_{w 3}}{2}+F_{h y}\left(h_{p}-h_{f 2}\right) \cos \theta \\
& \quad-\left(F_{y 5}+F_{y 6}\right) h_{r 2}-M_{h t} .
\end{aligned}
$$

The motions of longitudinal, lateral, yaw, and body roll of the tractor coupling with those of the trailer through the hitch point can, respectively, be expressed by

$$
\begin{aligned}
v_{x 2} & =v_{x 1} \cos \theta, \\
v_{y 2} & =\left(v_{y 1}-l_{p} \gamma_{1}\right) \cos \theta-a_{2} \gamma_{2}-v_{x 1} \sin \theta, \\
\gamma_{2} & =\gamma_{1}+\dot{\theta} \\
M_{h t} & =K_{h t}\left(\phi_{2}-\phi_{1} \cos \theta\right) .
\end{aligned}
$$

2.2. Suspension Model. Suspension model is used to predict the lateral load transfer as cornering which affects the variation of the tyre normal force. The primary components of the suspension used in this study comprise the leaf spring and the damping. The actual suspension force which is much nonlinear with respect to the deformation of the spring is calculated as follows [18]:

$$
\Delta F_{z i}^{\mathrm{lat}}= \begin{cases}K_{s 11} e_{i}+K_{s 12} e_{i}^{5}+D_{s 1} \dot{e}_{i}, & i=1,2, \\ K_{s 21} e_{i}+K_{s 22} e_{i}^{5}+D_{s 2} \dot{e}_{i}, & i=3,4, \\ K_{s 31} e_{i}+K_{s 32} e_{i}^{5}+D_{s 3} \dot{e}_{i}, & i=5,6,\end{cases}
$$

where $K_{s m n}, D_{\text {smn }}(m, n=1,2,3)$, respectively, denote the stiff and damping coefficients and $e_{i}, \dot{e}_{i}$, respectively, are the deformation and deformation rate of the $i$ th suspension which can be expressed in detail as

$$
\begin{aligned}
& e_{1}=\frac{t_{w 1}}{2} \phi_{1}, \\
& e_{2}=-\frac{t_{w 1}}{2} \phi_{1},
\end{aligned}
$$




$$
\begin{aligned}
e_{3}= & \frac{t_{w 2}}{2} \phi_{1}, \\
e_{4}= & -\frac{t_{w 2}}{2} \phi_{1}, \\
e_{5}= & \left(\frac{t_{w 3}}{2} \phi_{2}\right) \cos \theta+l_{2} \phi_{2} \sin \theta, \\
e_{6}= & -\left(\frac{t_{w 3}}{2} \phi_{2}\right) \cos \theta+l_{2} \phi_{2} \sin \theta, \\
\dot{e}_{1}= & \frac{t_{w 1}}{2} \dot{\phi}_{1}, \\
\dot{e}_{2}= & -\frac{t_{w 1}}{2} \dot{\phi}_{1}, \\
\dot{e}_{3}= & \frac{t_{w 2}}{2} \dot{\phi}_{1}, \\
\dot{e}_{4}= & -\frac{t_{w 2}}{2} \dot{\phi}_{1}, \\
\dot{e}_{5}= & \left(\frac{t_{w 3}}{2} \dot{\phi}_{2}\right) \cos \theta-\left(\frac{t_{w 3}}{2} \phi_{2}\right) \dot{\theta} \sin \theta+l_{2} \dot{\phi}_{2} \sin \theta \\
& +l_{2} \phi_{2} \dot{\theta} \cos \theta, \\
\dot{e}_{6}= & -\left(\frac{t_{w 3}}{2} \dot{\phi}_{2}\right) \cos \theta+\left(\frac{t_{w 3}}{2} \phi_{2}\right) \dot{\theta} \sin \theta+l_{2} \dot{\phi}_{2} \sin \theta \\
& +l_{2} \phi_{2} \dot{\theta} \cos \theta
\end{aligned}
$$

2.3. Tyre Model. Tyre normal load as one of the key factors influencing the tyre force should be well modeled. Particularly, the longitudinal and lateral load transfer should be precisely predicted. With these in mind, the tyre normal loads are calculated as

$$
\begin{aligned}
F_{z 1}= & \frac{m_{1} g b_{1}}{2 l_{1}}+\frac{m_{2} g b_{2}\left(b_{1}-l_{p}\right)}{2 l_{1} l_{2}} \\
& -\frac{1}{2}\left(\frac{m_{1} a_{x 1} h_{c 1}}{l_{1}}+\frac{m_{2} a_{x 2} h_{c 2}\left(b_{1}-l_{p}\right)}{l_{1} l_{2}}\right) \\
& +\Delta F_{z 1}^{\text {lat }}, \\
F_{z 2}= & \frac{m_{1} g b_{1}}{2 l_{1}}+\frac{m_{2} g b_{2}\left(b_{1}-l_{p}\right)}{2 l_{1} l_{2}} \\
& -\frac{1}{2}\left(\frac{m_{1} a_{x 1} h_{c 1}}{l_{1}}+\frac{m_{2} a_{x 2} h_{c 2}\left(b_{1}-l_{p}\right)}{l_{1} l_{2}}\right) \\
& +\Delta F_{z 2}^{\text {lat }}, \\
F_{z 3}= & \frac{m_{1} g a_{1}}{2 l_{1}}+\frac{m_{2} g b_{2}\left(a_{1}+l_{p}\right)}{2 l_{1} l_{2}}+\frac{m_{1} a_{x 1} h_{c 1}}{2 l_{1}} \\
& -\frac{m_{2} a_{x 2} h_{c 2}\left(a_{1}+l_{p}\right)}{2 l_{1} l_{2}}+\Delta F_{z 3}^{\text {lat }},
\end{aligned}
$$

$$
\begin{aligned}
F_{z 4}= & \frac{m_{1} g a_{1}}{2 l_{1}}+\frac{m_{2} g b_{2}\left(a_{1}+l_{p}\right)}{2 l_{1} l_{2}}+\frac{m_{1} a_{x 1} h_{c 1}}{2 l_{1}} \\
& -\frac{m_{2} a_{x 2} h_{c 2}\left(a_{1}+l_{p}\right)}{2 l_{1} l_{2}}+\Delta F_{z 4}^{\text {lat }}, \\
F_{z 5}= & \frac{m_{2} g a_{2}}{2 l_{2}}+\frac{m_{2} a_{x 2} h_{c 2}}{2 l_{2}}+\Delta F_{z 5}^{\text {lat }}, \\
F_{z 6}= & \frac{m_{2} g a_{2}}{2 l_{2}}+\frac{m_{2} a_{x 2} h_{c 2}}{2 l_{2}}+\Delta F_{z 6}^{\text {lat }},
\end{aligned}
$$

where $\Delta F_{z i}^{\text {lat }}$ is the variation of normal force on the $i$ th wheel caused by lateral load transfer and can be derived from (10).

Slip angle and longitudinal slip ratio for each wheel are, respectively, defined by

$$
\begin{aligned}
& \alpha_{1}=\delta_{f}-\arctan \left(\frac{v_{y 1}+a_{1} \gamma_{1}}{v_{x w 1}}\right), \\
& \alpha_{2}=\delta_{f}-\arctan \left(\frac{v_{y 1}+a_{1} \gamma_{1}}{v_{x w 2}}\right) \text {, } \\
& \alpha_{3}=-\arctan \left(\frac{v_{y 1}-b_{1} \gamma_{1}}{v_{x w 3}}\right) \text {, } \\
& \alpha_{4}=-\arctan \left(\frac{v_{y 1}-b_{1} \gamma_{1}}{v_{x w 4}}\right) \text {, } \\
& \alpha_{5}=\theta \\
& -\arctan \left(\frac{-v_{x 1} \sin \theta+\left(v_{y 1}-l_{p} \gamma_{1}\right) \cos \theta-l_{2}\left(\gamma_{1}+\dot{\theta}\right)}{v_{x w 5}}\right), \\
& \alpha_{6}=\theta \\
& -\arctan \left(\frac{-v_{x 1} \sin \theta+\left(v_{y 1}-l_{p} \gamma_{1}\right) \cos \theta-l_{2}\left(\gamma_{1}+\dot{\theta}\right)}{v_{x w 6}}\right), \\
& \lambda_{1}=\frac{R_{w 1} \omega_{w 1}-\left(v_{x 1}-\left(t_{w 1} / 2\right) \gamma_{1}\right)}{v_{x w 1}}, \\
& \lambda_{2}=\frac{R_{w 1} \omega_{w 2}-\left(v_{x 1}+\left(t_{w 1} / 2\right) \gamma_{1}\right)}{v_{x w 2}}, \\
& \lambda_{3}=\frac{R_{w 2} \omega_{w 3}-\left(v_{x 1}-\left(t_{w 2} / 2\right) \gamma_{1}\right)}{v_{x w 3}}, \\
& \lambda_{4}=\frac{R_{w 2} \omega_{w 4}-\left(v_{x 1}+\left(t_{w 2} / 2\right) \gamma_{1}\right)}{v_{x w 4}}, \\
& \lambda_{5}=\frac{R_{w 3} \omega_{w 5}}{v_{x w 5}} \\
& -\frac{v_{x 1} \cos \theta+\left(v_{y 1}-l_{p} \gamma_{1}\right) \sin \theta-\left(t_{w 3} / 2\right)\left(\gamma_{1}+\dot{\theta}\right)}{v_{x w 5}},
\end{aligned}
$$




$$
\begin{aligned}
\lambda_{6}= & \frac{R_{w 3} \omega_{w 6}}{v_{x w 6}} \\
- & \frac{v_{x 1} \cos \theta+\left(v_{y 1}-l_{p} \gamma_{1}\right) \sin \theta+\left(t_{w 3} / 2\right)\left(\gamma_{1}+\dot{\theta}\right)}{v_{x w 6}},
\end{aligned}
$$

where $v_{x w i}$ is the forward velocity of the wheel center in the wheel plane:

$$
\begin{aligned}
& v_{x w 1}=v_{x 1}-\frac{t_{w 1}}{2} \gamma_{1}, \\
& v_{x w 2}=v_{x 1}+\frac{t_{w 1}}{2} \gamma_{1}, \\
& v_{x w 3}=v_{x 1}-\frac{t_{w 2}}{2} \gamma_{1}, \\
& v_{x w 4}=v_{x 1}+\frac{t_{w 2}}{2} \gamma_{1}, \\
& v_{x w 5}=v_{x 1} \cos \theta+\left(v_{y 1}-l_{p} \gamma_{1}\right) \sin \theta-\frac{t_{w 3}}{2}\left(\gamma_{1}+\dot{\theta}\right), \\
& v_{x w 6}=v_{x 1} \cos \theta+\left(v_{y 1}-l_{p} \gamma_{1}\right) \sin \theta+\frac{t_{w 3}}{2}\left(\gamma_{1}+\dot{\theta}\right) .
\end{aligned}
$$

Tyre force as one of the most important factors affecting vehicle dynamics is strongly nonlinear in critical situations. In order to capture the actual properties of the tyre force, a nonlinear tyre model should be introduced. With the tyre normal force, tyre slip angle, and longitudinal slip ratio modeled above, the nonlinear tyre forces can be obtained by the Dugoff tyre model [19] as follows.

Longitudinal tyre force is as follows:

$$
F_{x i}= \begin{cases}\frac{C_{x f} \lambda_{i}}{1-\lambda_{i}} f\left(S_{i}\right), & i=1,2, \\ \frac{C_{x r} \lambda_{i}}{1-\lambda_{i}} f\left(S_{i}\right), & i=3,4, \\ \frac{C_{x t} \lambda_{i}}{1-\lambda_{i}} f\left(S_{i}\right), & i=5,6 .\end{cases}
$$

Lateral tyre force is as follows:

$$
F_{y i}= \begin{cases}\frac{C_{y f} \tan \alpha_{i}}{1-\lambda_{i}} f\left(S_{i}\right), & i=1,2, \\ \frac{C_{y r} \tan \alpha_{i}}{1-\lambda_{i}} f\left(S_{i}\right), & i=3,4, \\ \frac{C_{y t} \tan \alpha_{i}}{1-\lambda_{i}} f\left(S_{i}\right), & i=5,6,\end{cases}
$$

where

$S_{i}$

$$
\begin{aligned}
& = \begin{cases}\frac{\mu F_{z i}\left(1-\varepsilon_{r} v_{x w i} \sqrt{\lambda_{i}{ }^{2}+\tan ^{2} \alpha_{i}}\right)}{2 \sqrt{C_{x f}{ }^{2} \lambda_{i}{ }^{2}+C_{y f}{ }^{2} \tan ^{2} \alpha_{i}}}\left(1-\lambda_{i}\right), & i=1,2, \\
\frac{\mu F_{z i}\left(1-\varepsilon_{r} \nu_{x w i} \sqrt{\lambda_{i}^{2}+\tan ^{2} \alpha_{i}}\right)}{2 \sqrt{C_{x r}{ }^{2} \lambda_{i}{ }^{2}+C_{y r}{ }^{2} \tan ^{2} \alpha_{i}}}\left(1-\lambda_{i}\right), & i=3,4, \\
\frac{\mu F_{z i}\left(1-\varepsilon_{r} v_{x w i} \sqrt{\lambda_{i}{ }^{2}+\tan ^{2} \alpha_{i}}\right)}{2 \sqrt{C_{x t}{ }^{2} \lambda_{i}{ }^{2}+C_{y t}{ }^{2} \tan ^{2} \alpha_{i}}}\left(1-\lambda_{i}\right), & i=5,6,\end{cases} \\
& f\left(S_{i}\right)= \begin{cases}1, & S_{i}>1, \\
S_{i}\left(2-S_{i}\right), & S_{i}<1 .\end{cases}
\end{aligned}
$$

For tyre $i$ with active brake torque $T_{b i}$, the rotational dynamics can be formulated as

$$
I_{w i} \dot{\omega}_{w i}=-T_{b i}-R_{w i} F_{x i}, \quad i=1,2, \ldots, 6 .
$$

In this work, brake torque is the output of the proposed control scheme to generate an appropriate brake force on the wheel. In order to capture the dynamic behavior of the pneumatic braking actuator, a second-order model is taken into account here; consequently, the actual output of brake torque is given as

$$
T_{b i}=\frac{T_{b i}^{\text {ref }}}{\xi_{1} s^{2}+\xi_{2} s+1},
$$

where $T_{b i}{ }^{\text {ref }}$ is the reference brake torque output from the controller and $s$ is Laplace operator. $\xi_{1}, \xi_{2}$ are constant which dominate the dynamic response and mainly relate to the physical property of the brake actuator system. Obviously, the actual value of $\xi_{1}, \xi_{2}$ depends on a certain braking system; however, it is not our concern here, and we take $\xi_{1}=1 / 300$, $\xi_{2}=1 / 12$ in general.

\section{Controller Design}

3.1. Description of the Control Scheme. The lateral dynamics of the tractor semitrailer vehicle are stabilized by a corrective yaw moment generated by active wheel braking. The whole control scheme is a two-layer structure with an upper yaw moment controller and a lower brake force distributor. The upper controller is designed based on fuzzy logic method to determine the corrective yaw moments, respectively, for the tractor and the trailer to stabilize the yaw dynamics. The lower brake force distributor consisting of a set of rules is designed to determinate the target braking wheel and the amount of brake torque corresponding to the corrective yaw moment from the upper controller. The block diagram of the whole control scheme is illustrated in Figure 3. In this scheme, the reference model using a linear tractor-trailer model is designed to generate the reference responses that are the yaw 


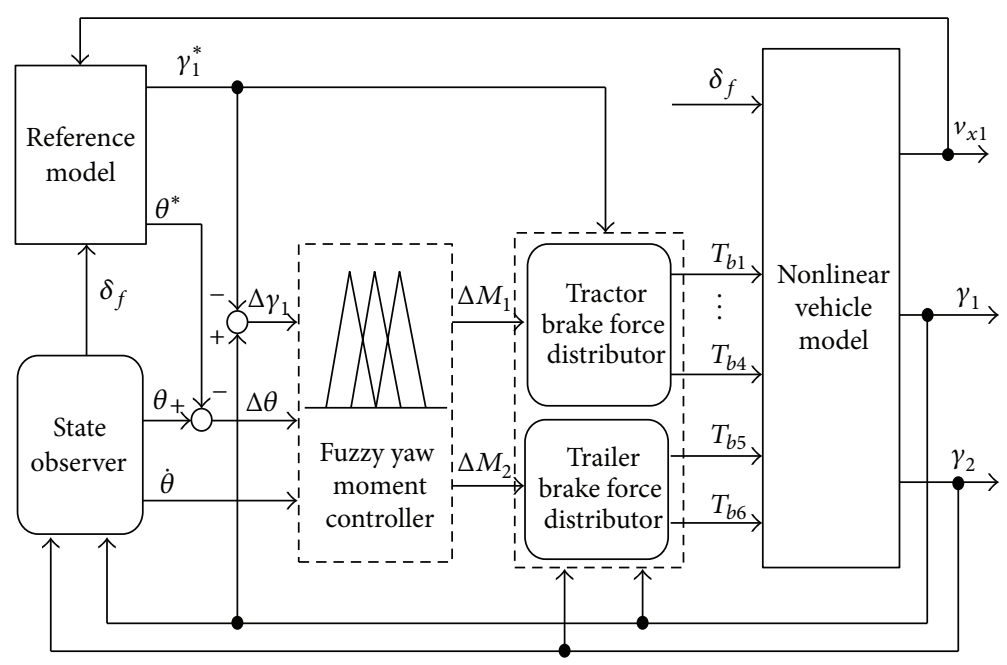

FIGURE 3: Block diagram of the control scheme.

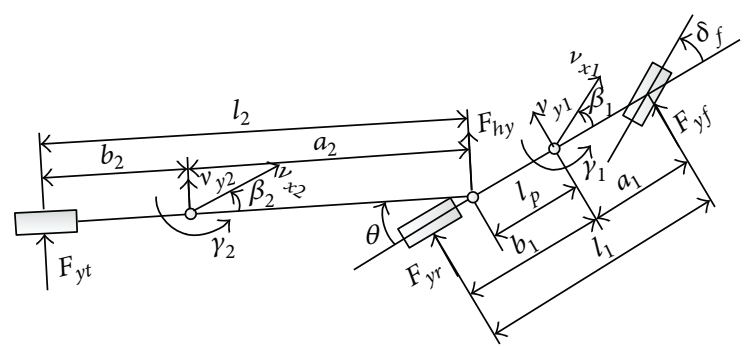

FIGURE 4: Simplified linear schematic model of a typical tractortrailer combination.

rate of the tractor and the hitch angle between the tractor and the trailer. The actual response of yaw rate can be measured by sensors while the states of hitch angle and the hitch angular rate can be estimated by an observer from the yaw rate responses of the tractor and the trailer according to the relationship given in (8). However, the state estimation is a special issue and it is not a main concern in this work, so we assume the hitch angle and angular rate can be directly acquired. The upper fuzzy yaw moment controller consists of two subcontrollers, respectively, for the tractor and the trailer which are designed separately based on fuzzy logic. The nonlinear vehicle model which is constructed in Section 2 replaces the reallife tractor semitrailer vehicle to evaluate the performance of the proposed control scheme by simulations.

3.2. Reference Responses. The reference responses are the steady-state yaw rate of the tractor and the hitch angle between the tractor and trailer. The steady-state reference responses are derived from a linear tractor-trailer combination model shown in Figure 4 [7,20]. First, assuming that the longitudinal velocity for the tractor equals that of the trailer, that is, $v_{x 1}=v_{x 2}=v_{x}$, the steady-state response of the tractor's yaw rate can be expressed as

$$
\gamma_{1 t}^{*}=\frac{v_{x} / l_{1}}{1+K_{s} v_{x}^{2}} \delta_{f}
$$

where $K_{s}$ is a yaw stability factor with

$$
\begin{aligned}
K_{s}= & \frac{b_{1} l_{2} m_{1}+\left(b_{1}-l_{p}\right) b_{2} m_{2}}{l_{1}^{2} l_{2} C_{y 1}} \\
& -\frac{a_{1} l_{2} m_{1}+\left(a_{1}+l_{p}\right) b_{2} m_{2}}{l_{1}^{2} l_{2} C_{y 2}},
\end{aligned}
$$

where $C_{y 1}, C_{y 2}$ are, respectively, the linear cornering stiffness of the front and rear tyre of the tractor. In fact, the maximum lateral acceleration a vehicle can acquire as cornering is constrained by the limit of adhesion between the tyre and the road. Therefore, the reference response of the tractor's yaw rate to driver's steer input cannot always be obtained, so it should be bounded by

$$
\left|\gamma_{1 t}^{*}\right| \leq \frac{\mu g}{v_{x}}
$$

So the reference response of the tractor's yaw rate is rewritten as

$$
\gamma_{1}^{*}= \begin{cases}\gamma_{1 t}{ }^{*}, & \left|\gamma_{1 t}{ }^{*}\right|<\frac{\mu g}{v_{x}}, \\ \frac{\mu g}{v_{x}}, & \left|\gamma_{1 t}{ }^{*}\right| \geq \frac{\mu g}{v_{x}} .\end{cases}
$$

Similarly, the reference response of the hitch angle in steady state which can also be obtained from the linear model described in Figure 4 is given as

$$
\theta^{*}=\frac{p_{1}+\left(p_{2}+p_{3}\right) v_{x}{ }^{2}}{1+K_{s} v_{x}{ }^{2}} \delta_{f},
$$

with

$$
p_{1}=-\frac{l_{p}-b_{1}+l_{2}}{l_{1}},
$$




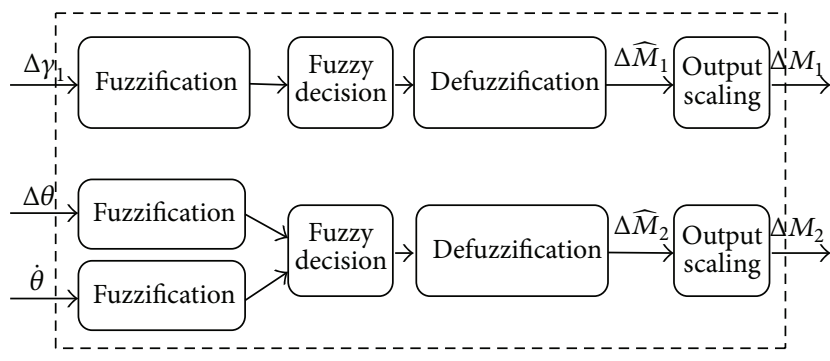

FIGURE 5: Schematic of the upper yaw moment controller based on fuzzy logic.

$$
\begin{aligned}
& p_{2}=\frac{a_{2} m_{2}}{l_{1} l_{2} C_{y 3}}, \\
& p_{3}=-\frac{a_{1} l_{2} m_{1}+\left(a_{1}+l_{p}\right) b_{2} m_{2}}{l_{1}{ }^{2} l_{2} C_{y 2}},
\end{aligned}
$$

where $C_{y_{3}}$ is the linear cornering stiffness of the trailer tyre and $K_{s}$ is the same as that in (21).

3.3. Upper Yaw Moment Controller. The upper yaw moment controller is designed based on fuzzy logic control method to determine the corrective yaw moments according to the reference and the actual responses to keep the lateral stability of a tractor semitrailer combination. The upper yaw moment controller, as shown in Figure 5, consists of two parts. One is for the tractor with the yaw rate error as the input and the corrective yaw moment for the tractor as the output and the other is for the trailer with the hitch angle error and the hitch angular rate as the inputs and the corrective yaw moment for the trailer as the output.

The design of the fuzzy controller here based on MATLAB fuzzy toolbox includes the processes of fuzzification, fuzzy decision, defuzzification, and output scaling. As the first step of a fuzzy controller design, fuzzification makes the inputs dimensionally compatible with the condition of the knowledge-based rules using linguistic variables. Five different levels are defined for each input and each output membership functions with the linguistic terms "NB," "NS," "ZE," "PS," and "PB," respectively, representing "Negative Big," "Negative Small," "Zero," "Positive Small," and "Positive Big." Fuzzy decision processes a set of rules based on the prepared rule base given in Tables 1 and 2, respectively, for the tractor and the trailer to produce fuzzy output. The membership functions of the input and output variables, respectively, for the tractor and the trailer are shown in Figures 6 and 7. Mamdani inference method is used for implementing the inference mechanism and centroid algorithm is used for the defuzzification process. The output of defuzzification is the normalized corrective yaw moments $\Delta M_{10}$ and $\Delta M_{20}$ in the range of $[-1,1]$, respectively, for the tractor and the trailer. Consequently, the derived fuzzy input-output curves for the tractor and trailer are, respectively, shown in Figures 8 and 9. Then,
TABLE 1: Tractor yaw moment controller rule base.

\begin{tabular}{lc}
\hline$\Delta \gamma_{1}$ & $\Delta M_{10}$ \\
\hline NB & PB \\
NS & PS \\
ZE & ZE \\
PS & NS \\
PB & NB \\
\hline
\end{tabular}
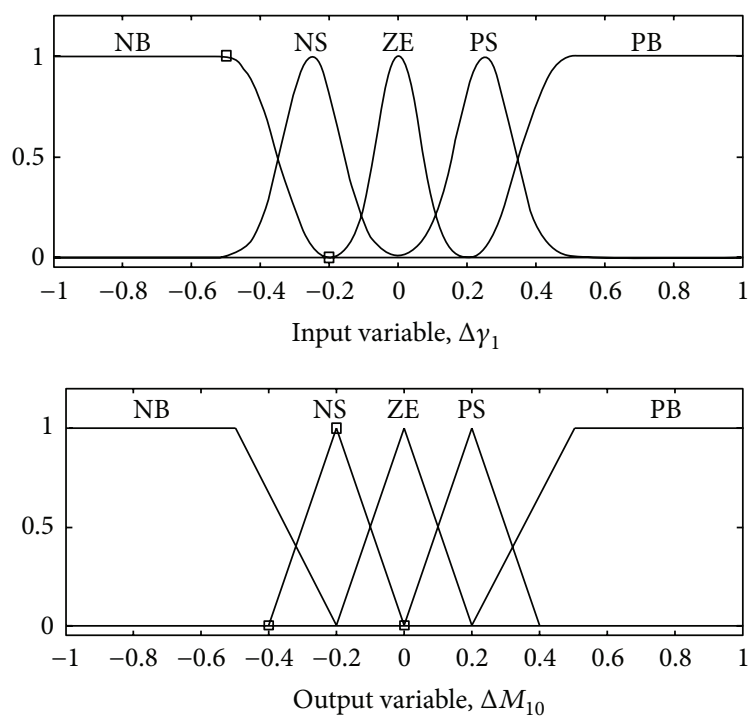

FIGURE 6: Membership function for the input and output variables of the tractor.

the actual corrective yaw moments for the tractor and the trailer are calculated by

$$
\begin{aligned}
& \Delta M_{1}=k_{M 1} \Delta M_{10}, \\
& \Delta M_{2}=k_{M 2} \Delta M_{20},
\end{aligned}
$$

where $k_{M 1}, k_{M 2}$ are the scaling factors decided by trials.

3.4. Distribution of Brake Force. The lower part of the proposed control scheme is the distribution of brake force to realize the corrective yaw moment from the upper fuzzy yaw moment controller. It is known that the lateral dynamics of a vehicle can be stabilized by individual wheel braking according to the concept of ESC for passenger cars so that oversteer (OS) and understeer (US) can be corrected, respectively, by braking the outside front wheel and the inside rear wheel [21]. Therefore, the lateral stability of the tractor semitrailer vehicle can be improved by separate control of the tractor and the trailer. Further, for the tractor, brake the outside front wheel to correct OS and brake the inside rear wheel to correct US, and for the trailer, brake the outside wheel to correct OS and brake the inside wheel to correct US. With the assumptions of the dual-tyres for the tractor and the trailer in Figure 2 being simplified as a single one, the detail decisions on the target braking wheel for the tractor and the trailer are, respectively, given in Tables 3 and 4, where " 1 ," " 2 ," " 3 ," and " 4 " in Table 3, respectively, represent the tractor wheel of 
TABLE 2: Trailer yaw moment controller rule base.

\begin{tabular}{lllllllcc}
\hline$\Delta \theta$ & $\dot{\theta}$ & $\Delta M_{20}$ & $\Delta \theta$ & $\dot{\theta}$ & $\Delta M_{20}$ & $\Delta \theta$ & $\dot{\theta}$ \\
\hline PB & PB & NB & PS & NB & PB & PB & ZE & NB \\
PS & PB & NB & PS & NS & PS & PS & ZE & NS \\
ZE & PB & NS & PS & ZE & ZE & NB & NB \\
PB & PS & NB & ZE & NB & PB & NS & NB \\
PS & PS & NB & ZE & PS & PS & ZE & NB & PB \\
ZE & PS & NS & NB & PB & NS & NB & NS \\
PB & ZE & NB & NB & PS & ZE & NS & NS \\
PS & ZE & NS & NB & ZE & PS & ZE & NS \\
NB & PB & PS & NS & PB & NB & NB & ZE \\
NS & PB & ZE & NS & PS & NS & NS & ZE \\
ZE & PB & NS & NS & ZE & ZE & ZE & PE \\
\hline
\end{tabular}
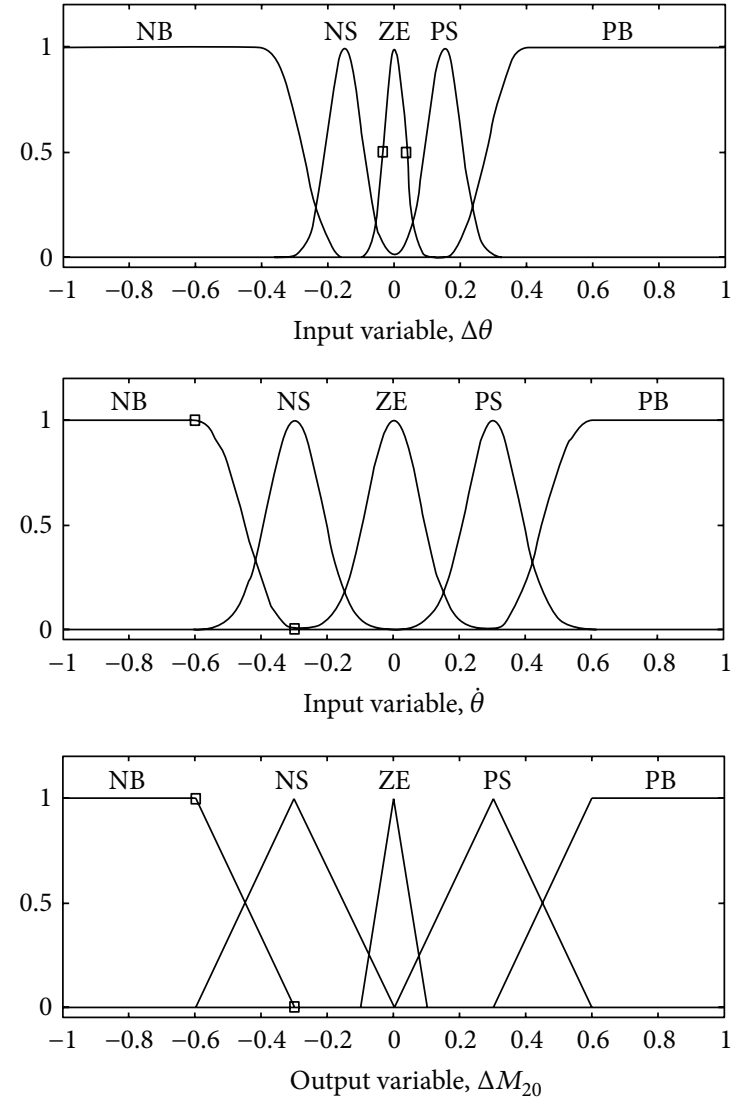

Figure 7: Membership function for the input and output variables of the trailer.

front left, front right, rear left, and rear right and " 5 ," " 6 " in Table 4, respectively, denote the left and right wheel of the trailer.

Generally, the brake torque regulator serves to determine the brake torque applied on the target wheel which can be derived directly from corrective yaw moment that is $\Delta T_{b}=2 \Delta M R_{w} / t_{w}$, where $R_{w}$ and $t_{w}$, respectively, denote the rolling radii and wheel track of the target brake wheel. However, if the brake torque corresponding to the corrective

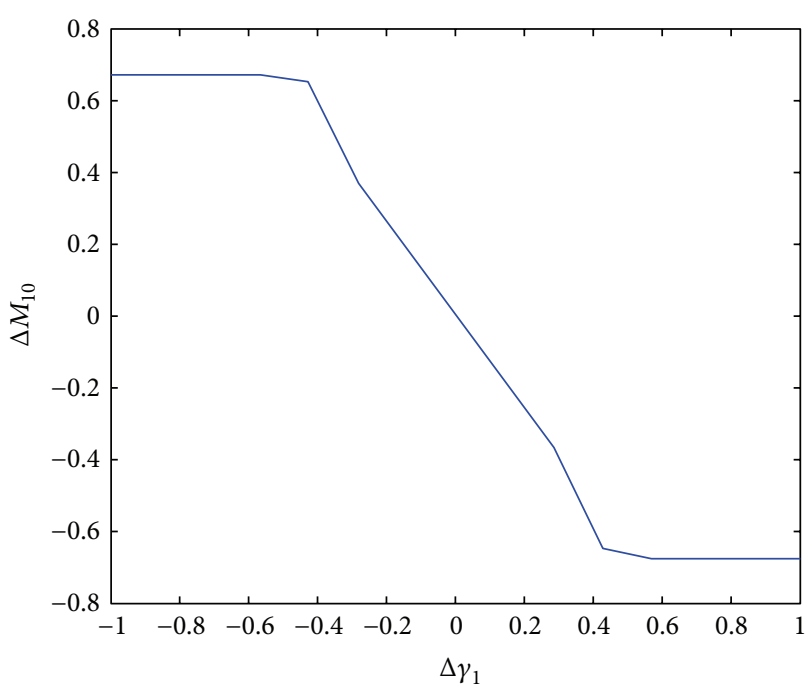

FIGURE 8: Fuzzy input-output curve for the tractor.

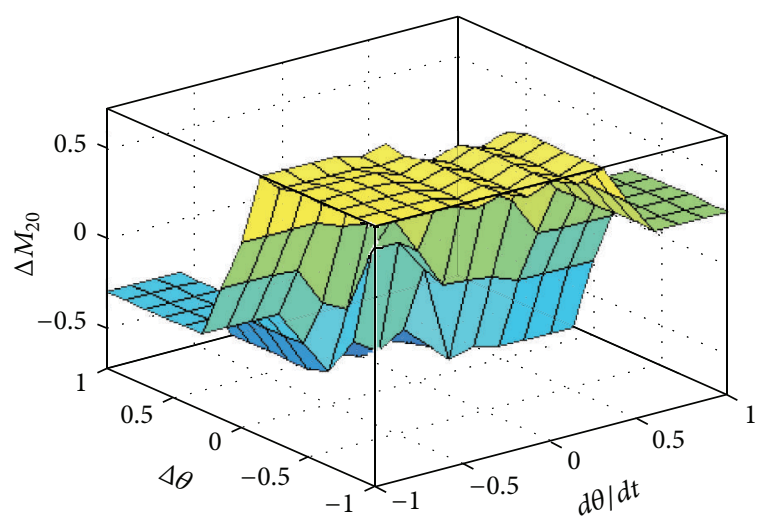

FIgURE 9: Fuzzy input-output curve for the trailer.

yaw moment makes the slip ratio of the target brake wheel increase rapidly over the reference slip ratio $\lambda^{*}$, a PI controller intervenes to regulate the brake torque to prevent the target brake wheel locking with the schematic block diagram given 


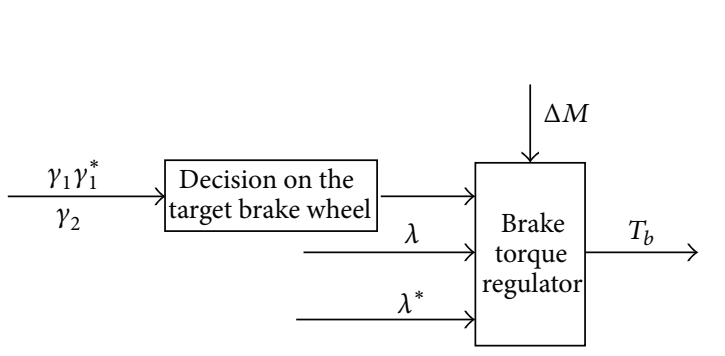

(a)

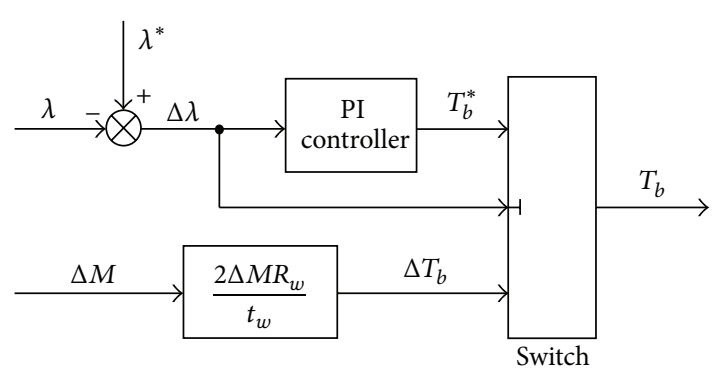

(b)

FIGURE 10: Realization of corrective yaw moment from the upper controller. (a) Whole realization scheme. (b) Brake torque regulator.

TABLE 3: Decision on the target brake wheel for the tractor.

\begin{tabular}{lccc}
\hline $\begin{array}{l}\text { Reference } \\
\text { yaw rate }\end{array}$ & $\begin{array}{c}\text { Actual yaw } \\
\text { rate }\end{array}$ & Comparison & $\begin{array}{c}\text { Target brake } \\
\text { wheel }\end{array}$ \\
\hline$\gamma_{1}^{*}>0$ & $\gamma_{1}>0$ & $\gamma_{1}^{*}<\gamma_{1}$ & 2 \\
$\gamma_{1}^{*}>0$ & $\gamma_{1}>0$ & $\gamma_{1}^{*}>\gamma_{1}$ & 3 \\
$\gamma_{1}^{*}>0$ & $\gamma_{1}>0$ & $\gamma_{1}^{*}=\gamma_{1}$ & - \\
$\gamma_{1}^{*}<0$ & $\gamma_{1}<0$ & $\gamma_{1}^{*}<\gamma_{1}$ & 4 \\
$\gamma_{1}^{*}<0$ & $\gamma_{1}<0$ & $\gamma_{1}^{*}>\gamma_{1}$ & 1 \\
$\gamma_{1}^{*}<0$ & $\gamma_{1}<0$ & $\gamma_{1}^{*}=\gamma_{1}$ & - \\
$\gamma_{1}^{*}>0$ & $\gamma_{1}<0$ & $\gamma_{1}^{*}>\gamma_{1}$ & 1 \\
$\gamma_{1}^{*}<0$ & $\gamma_{1}>0$ & $\gamma_{1}^{*}<\gamma_{1}$ & 2 \\
$\gamma_{1}^{*}=0$ & $\gamma_{1}<0$ & $\gamma_{1}^{*}>\gamma_{1}$ & 1 \\
$\gamma_{1}^{*}=0$ & $\gamma_{1}>0$ & $\gamma_{1}^{*}<\gamma_{1}$ & 2 \\
$\gamma_{1}^{*}>0$ & $\gamma_{1}=0$ & $\gamma_{1}^{*}>\gamma_{1}$ & 3 \\
$\gamma_{1}^{*}<0$ & $\gamma_{1}=0$ & $\gamma_{1}^{*}<\gamma_{1}$ & 4 \\
$\gamma_{1}^{*}=0$ & $\gamma_{1}=0$ & $\gamma_{1}^{*}=\gamma_{1}$ & - \\
\hline
\end{tabular}

"-" denotes no brake action.

TABLE 4: Decision on the target brake wheel for the trailer.

\begin{tabular}{lccc}
\hline $\begin{array}{l}\text { Reference } \\
\text { yaw rate }\end{array}$ & $\begin{array}{c}\text { Actual yaw } \\
\text { rate }\end{array}$ & Comparison & $\begin{array}{c}\text { Target brake } \\
\text { wheel }\end{array}$ \\
\hline$\gamma_{2}^{*}>0$ & $\gamma_{2}>0$ & $\gamma_{2}^{*}<\gamma_{2}$ & 6 \\
$\gamma_{2}^{*}>0$ & $\gamma_{2}>0$ & $\gamma_{2}^{*}>\gamma_{2}$ & 5 \\
$\gamma_{2}^{*}>0$ & $\gamma_{2}>0$ & $\gamma_{2}^{*}=\gamma_{2}$ & - \\
$\gamma_{2}^{*}<0$ & $\gamma_{2}<0$ & $\gamma_{2}^{*}<\gamma_{2}$ & 6 \\
$\gamma_{2}^{*}<0$ & $\gamma_{2}<0$ & $\gamma_{2}^{*}>\gamma_{2}$ & 5 \\
$\gamma_{2}^{*}<0$ & $\gamma_{2}<0$ & $\gamma_{2}^{*}=\gamma_{2}$ & - \\
$\gamma_{2}^{*}>0$ & $\gamma_{2}<0$ & $\gamma_{2}^{*}>\gamma_{2}$ & 5 \\
$\gamma_{2}^{*}<0$ & $\gamma_{2}>0$ & $\gamma_{2}^{*}<\gamma_{2}$ & 6 \\
$\gamma_{2}^{*}=0$ & $\gamma_{2}<0$ & $\gamma_{2}^{*}>\gamma_{2}$ & 5 \\
$\gamma_{2}^{*}=0$ & $\gamma_{2}>0$ & $\gamma_{2}^{*}<\gamma_{2}$ & 6 \\
$\gamma_{2}^{*}>0$ & $\gamma_{2}=0$ & $\gamma_{2}^{*}>\gamma_{2}$ & 5 \\
$\gamma_{2}^{*}<0$ & $\gamma_{2}=0$ & $\gamma_{2}^{*}<\gamma_{2}$ & 6 \\
$\gamma_{2}^{*}=0$ & $\gamma_{2}=0$ & $\gamma_{2}^{*}=\gamma_{2}$ & - \\
\hline
\end{tabular}

"-" denotes no brake action.

in Figure 10. The proportional gain is 10000 and integral gain is 200 in this PI controller.

\section{Simulations}

In this section, simulations are conducted to evaluate the proposed control scheme. Considering the two typical planar lateral instabilities jackknife and trailer oscillation and the rollover instability, three critical maneuvers that are external disturbance caused by jackknife, trailer oscillation, and a single lane change maneuver manipulated by the driver are taken into account to assess the proposed control scheme. The physical parameters characterizing the tractor semitrailer vehicle model in simulation are presented in Appendix B [22].

Firstly, the simulation for control of jackknife instability is presented. In this case, it is assumed that the vehicle runs straightly without any driver's steer input at an initial longitudinal velocity of $25 \mathrm{~m} / \mathrm{s}$ and suddenly suffers from an external lateral disturbance giving rise to an initial yaw rate of $0.1 \mathrm{rad} / \mathrm{s}$ on the trailer. In order to facilitate yielding a jackknife instability in simulation, the distance from the trailer centre of gravity (CG) to the hitch point is set as $a_{2}=$ $7.05 \mathrm{~m}$. In this transport condition, the tractor semitrailer will fall into jackknife with an initial trailer yaw rate of $0.1 \mathrm{rad} / \mathrm{s}$. The corresponding vehicle state response and comparisons are presented in Figure 11. The presented state responses comprise tractor yaw rate, trailer yaw rate, trailer slip angle, and the trailer roll angle. As we all know, there are many state variables related to the lateral dynamics of a tractor semitrailer vehicle; however, we only choose four state variables here for evaluation considering the space limit and we believe these four variables are enough to characterize the main lateral dynamics of a tractor semitrailer vehicle. The trajectory for this scenario is given in Figure 12. Active brake torque output by the controller and the corresponding longitudinal wheel slip ratio are, respectively, illustrated in Figures 13 and 14.

As shown in Figure 11, the states of the vehicle without control will be divergent monotonically and cannot return to the previous straight running any longer, so there is no doubt that the vehicle will lose stability quickly and fall into jackknife. Compared with the uncontrolled case, the vehicle with fuzzy yaw moment control detects the responding deviation from the reference values and then generates an appropriate corrective yaw moment, respectively, for the tractor and the trailer by active wheel braking to force the states to converge to zero. The effectiveness of the proposed control scheme can also be found from the trajectory response as shown in Figure 12. We can find that in the uncontrolled 

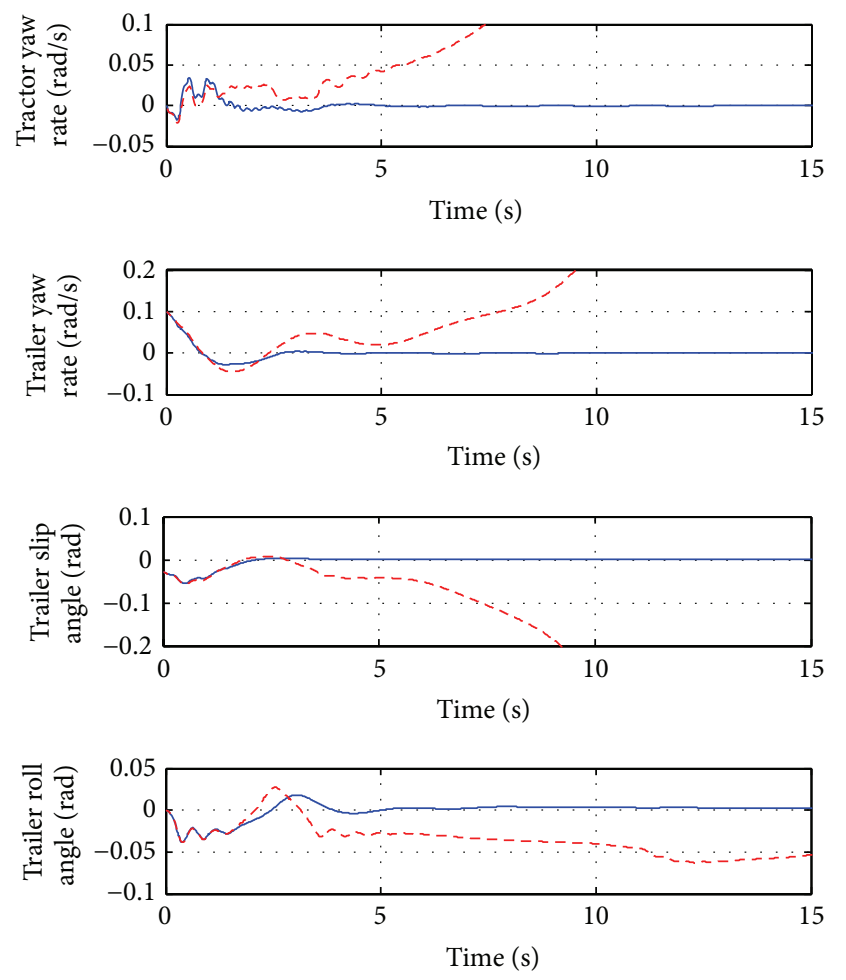

- Controlled

- - - Uncontrolled

FIGURE 11: State response and comparison for the jackknife case.

case the external disturbance causes the trailer a small lateral deviation (about $0.7 \mathrm{~m}$ ) from the origin, then fluctuates, and finally increases monotonically towards the opposite direction together with the tractor. Obviously, in the controlled case, the vehicle first experiences a small fluctuation on suffering the disturbance and then goes gradually towards its original directional line.

From the response of active brake torque in Figure 13, it is easy to observe that the active braking action is not necessarily very frequent and a small brake torque at a certain appropriate time may be rather important for keeping the lateral stability of the vehicle. In this scenario, any variation in direction for the tractor will be identified as OS since the vehicle runs straightly at the beginning, so the two front wheels of the tractor are primarily selected as the target braking wheel to generate a reverse yaw moment to prevent the tractor from falling into OS. The brake torque of the trailer is much larger than that of the tractor since the mass of the trailer is very large, so we can guess that the control of the trailer plays an important role in keeping lateral stability of the whole tractortrailer combination.

The second case of simulation presented in the following aims to evaluate the control performance when stabilizing a trailer oscillation instability. In this scenario, the vehicle is also assumed running straightly at an initial longitudinal velocity of $25 \mathrm{~m} / \mathrm{s}$ without any manipulation from the driver. On suffering a sudden external disturbance, an initial yaw rate of $0.1 \mathrm{rad} / \mathrm{s}$ is added to the trailer and then causes the vehicle to go into trailer oscillation. In simulation, the distance from the trailer CG to the hitch point is set as $a_{2}=10.50 \mathrm{~m}$ in order to facilitate yielding an oscillation on subjecting to the external disturbance. Two roads with different adhesion conditions are considered, with one of which is a dry road with an adhesion coefficient of 0.9 and the other is a slippery road with an adhesion coefficient of 0.35 . The vehicle state responses and comparisons for the two road conditions are given in Figures 15 and 16.

As shown in Figures 15 and 16, in this scenario, the external disturbance causes the trailer to oscillate in the lateral direction and further forces the whole tractor-trailer combination to oscillate. It is attributed to the backward movement of the trailer CG and the rearward amplification characteristic of a tractor-trailer combination. Obviously, with active control, the vehicle will first experience a small magnitude oscillation; then, the states converge to zero gradually and finally the vehicle recovers to its previous straight running, while in the uncontrolled case the oscillation magnitude will become larger and larger and a fatal accident seemed to be unavoidable. It is noticed that the control result is also rather satisfying on the slippery road, so we suppose that the proposed fuzzy logic controller is robust to the variation of road surface conditions.

The third simulation case is focused on a single lane change maneuver which is often used to assess the handling and stability performance of a vehicle at high speed. According to the actual steering input for a single lane change maneuver field test, a one-cycle sinusoidal signal given in Figure 17 is employed in this scenario as the steer angle on the front wheel to complete a single lane change maneuver simulation. Also, the control performance is assessed at an initial longitudinal velocity of $25 \mathrm{~m} / \mathrm{s}$ in two different adhesion conditions with coefficient of 0.9 for dry road and 0.35 for slippery road.

Figures 18-20, respectively, illustrate the comparisons of vehicle state, longitudinal velocity, and vehicle trajectory on the dry road. First, from the trajectory in Figure 20 combining with the state and velocity in Figures 18-19, we can see that if the vehicle has no control action, it would lose stability with very large transverse displacement and even finally run towards the transverse direction. No doubt the lane change maneuver cannot be completed and a fatal accident follows, while in the controlled case, a single lane change like trajectory is accomplished with an approximate maximum transverse displacement of $6 \mathrm{~m}$ which is closely associated with the vehicle speed and steer magnitude. Similar to the dry road case, the corresponding results for the slippery road case seen from Figures 21-23 are still satisfying with little effect from the great decrement of road adhesion, while the uncontrolled vehicle suffers rather obvious influence from the variation of road adhesion. So it is believed that the proposed control scheme is robust and can be effective in a rather wide range of road adhesion conditions.

\section{Conclusions}

In this study, a stability control scheme based on fuzzy logic method is proposed to improve the yaw stability and thereby 


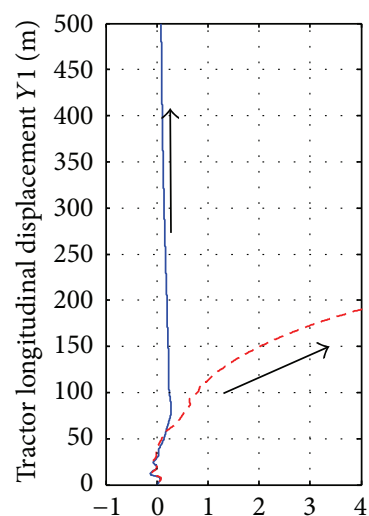

Tractor lateral displacement $X 1(\mathrm{~m})$

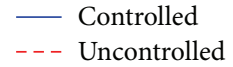

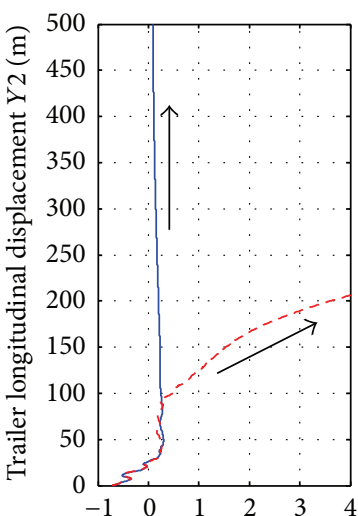

Trailer lateral displacement $X 2(\mathrm{~m})$

- Controlled

- - - Uncontrolled

FIGURE 12: Global trajectory and comparison for the jackknife case. Arrows in the figure represent the vehicle running direction.
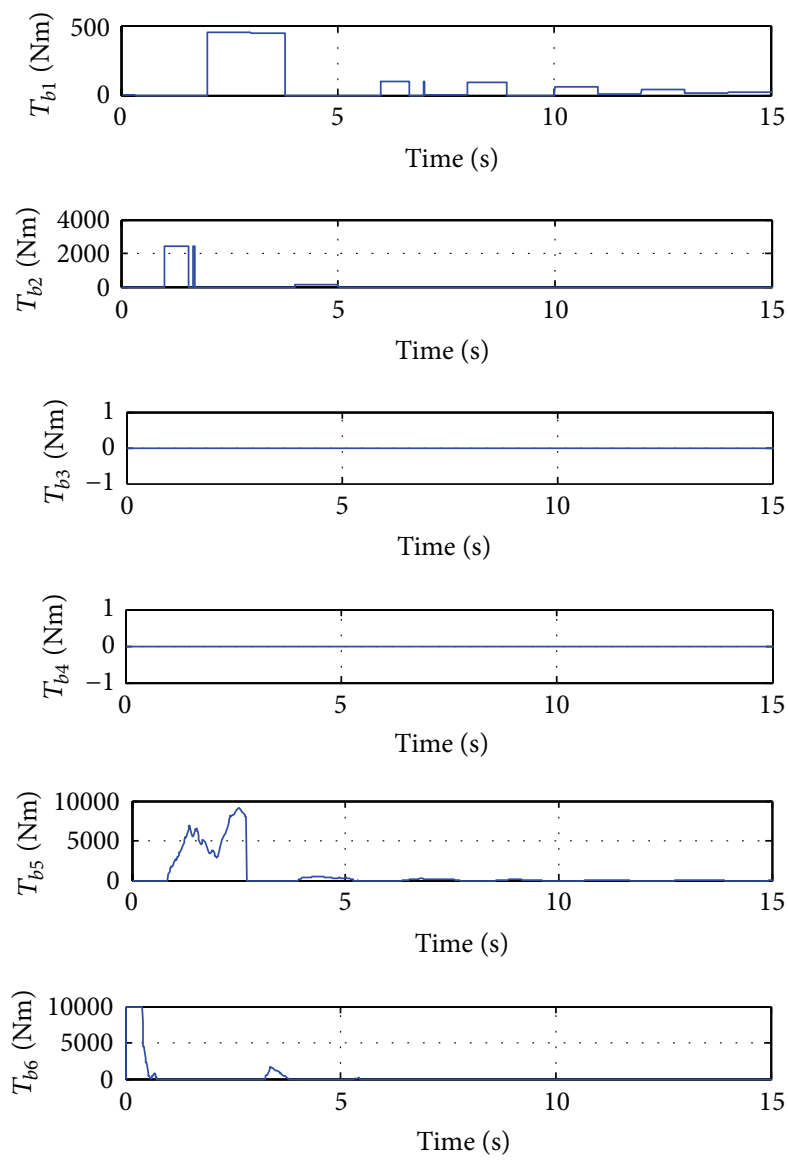

FiguRE 13: Active brake torque for the jackknife control case.

the roll stability of a tractor semitrailer vehicle in critical situations. The designed control scheme which is a two-layer structure comprises an upper fuzzy yaw moment controller and a lower brake force distributor. The upper fuzzy yaw moment controller further consists of two subcontrollers,
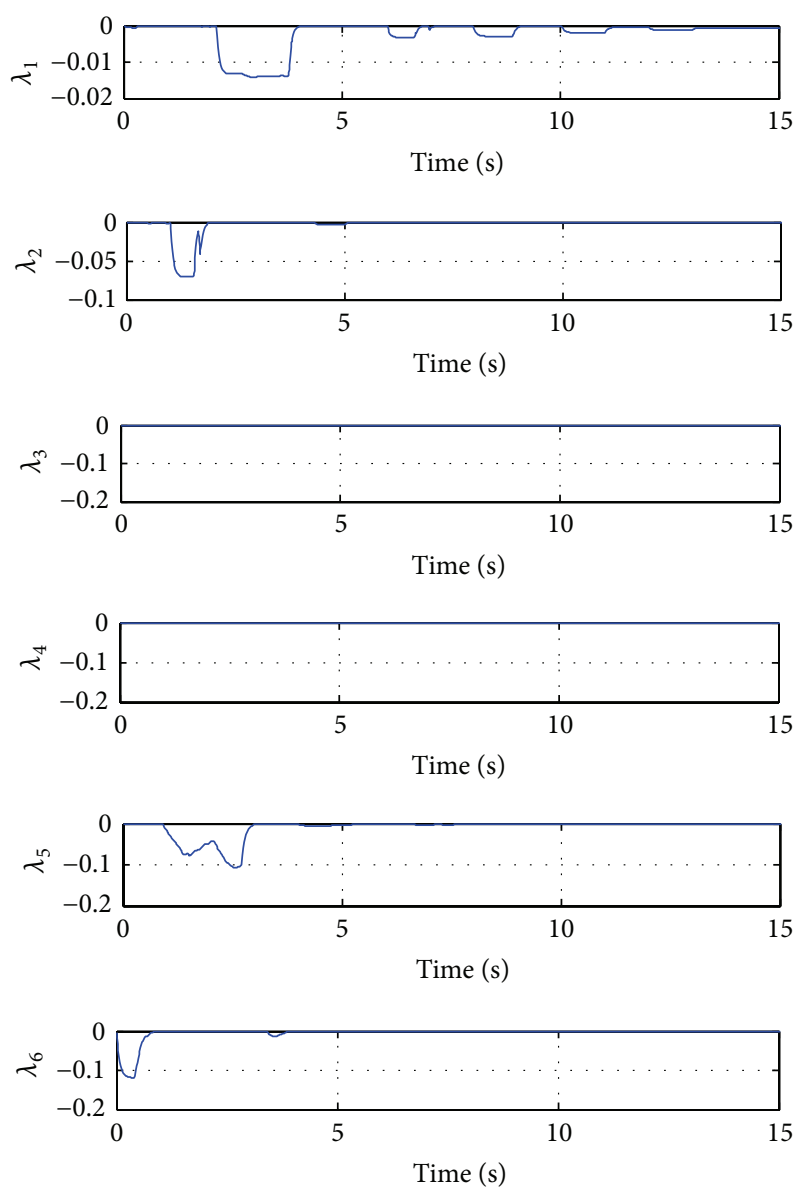

FIGURE 14: Longitudinal wheel slip ratio for the jackknife control case.

respectively, for the tractor and the trailer serving to stabilize the lateral stability of the tractor and the trailer separately by tracking the reference yaw rate of the tractor and the hitch angle between the tractor and the trailer. 

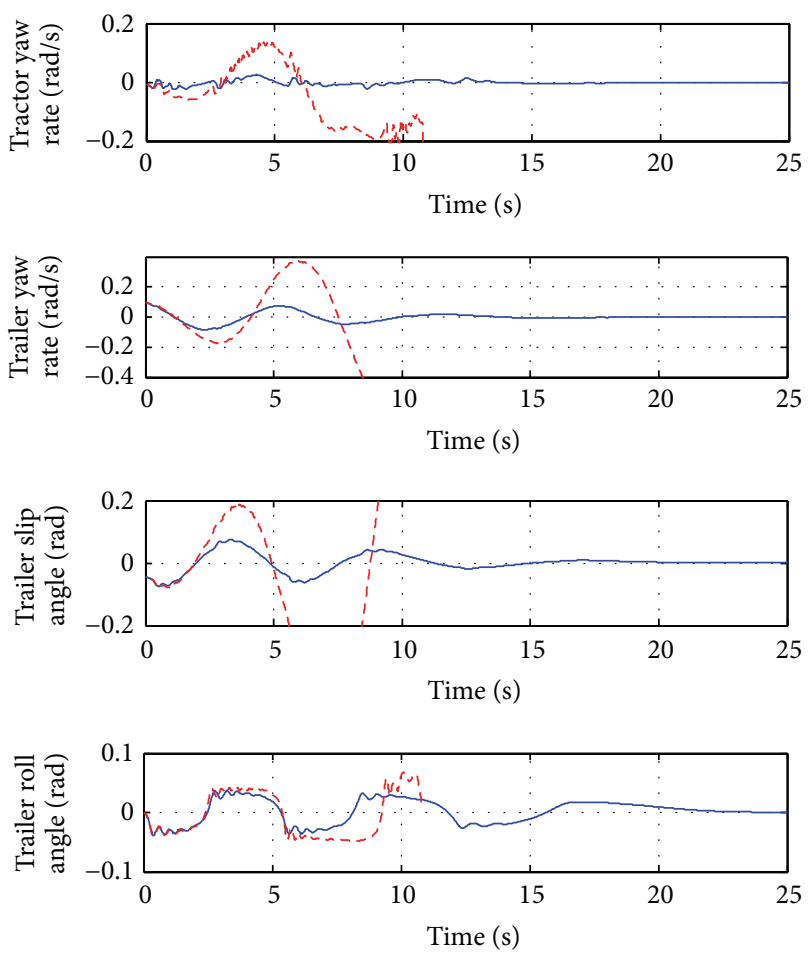

Controlled

- - Uncontrolled

FIGURE 15: State response and comparison for the trailer oscillation case on a dry road.
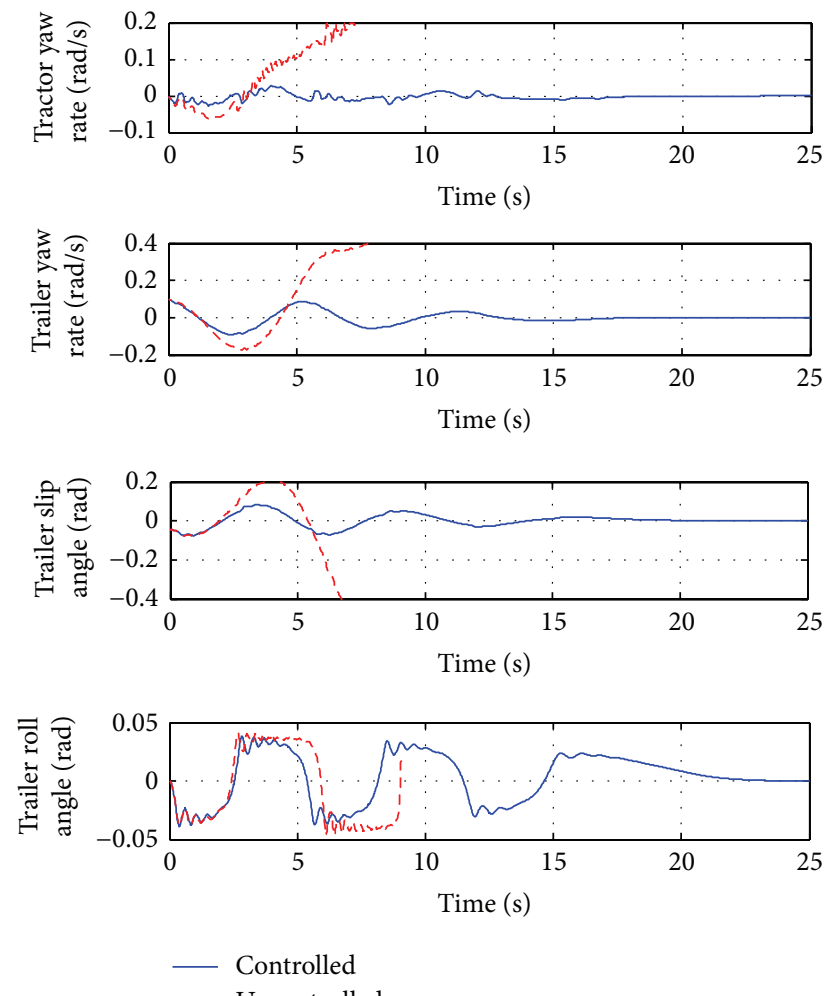

- - - Uncontrolled

FIGURE 16: State response and comparison for the trailer oscillation case on a slippery road.

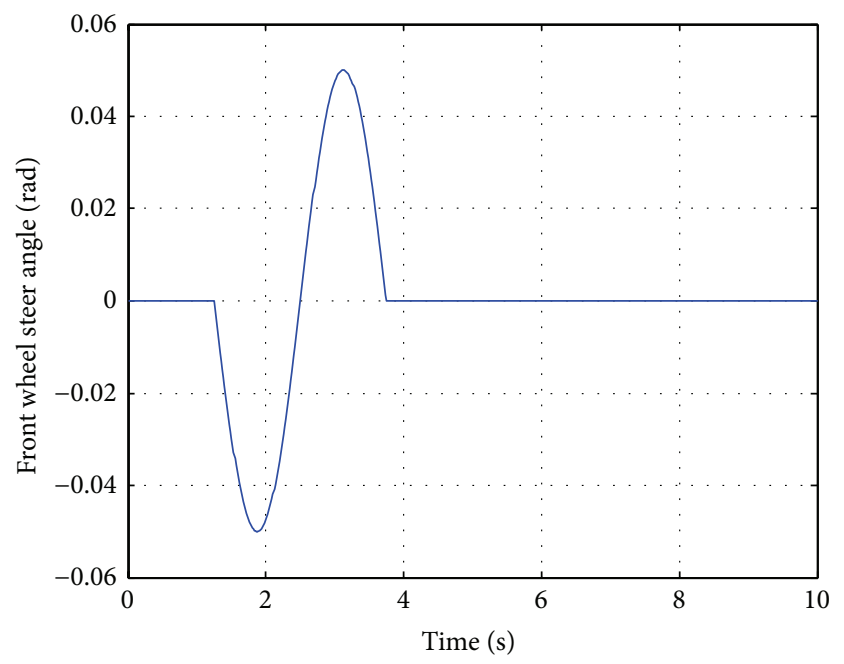

Figure 17: Front wheel steer angle for the single lane change maneuver.
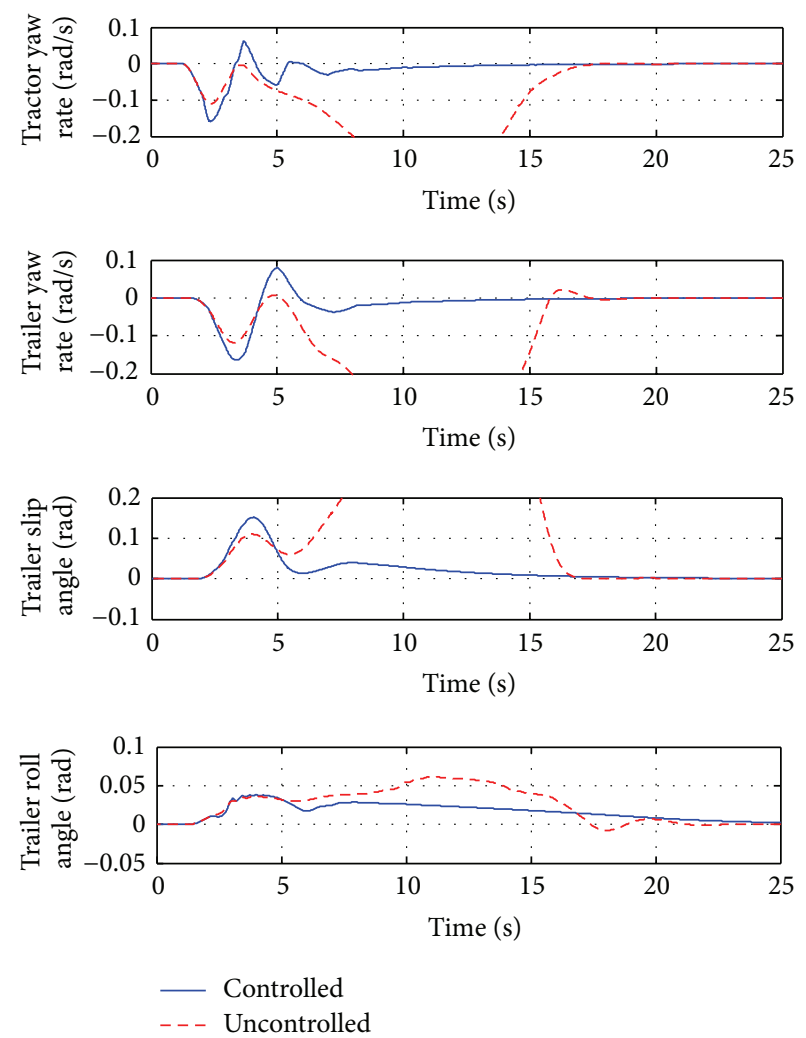

FIgURE 18: State and comparison for the single lane change maneuver on a dry road.

Several numerical simulations are conducted based on a nonlinear tractor semitrailer vehicle model to evaluate the controller. Two straight running with external disturbance maneuvers and a lane change maneuver are adopted and considering road adhesion conditions total five simulation scenarios are conducted to assess the control scheme comprehensively from stabilizing the LOC of jackknife and trailer 

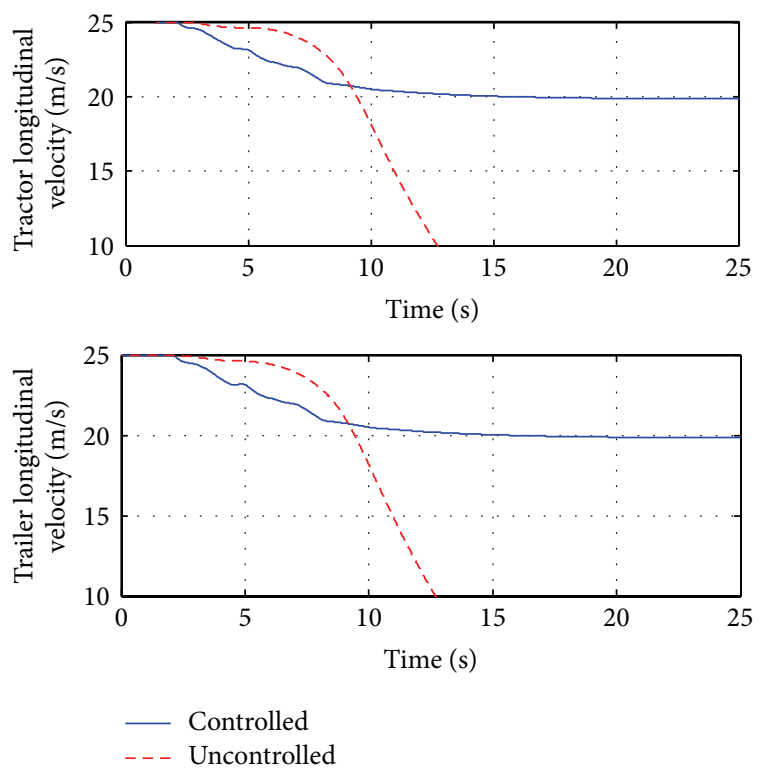

FIGURE 19: Longitudinal velocity for the single lane change maneuver on a dry road.

oscillation to the robust of the controller. The results demonstrate that an active control is very important to keep the lateral stability of a tractor semitrailer and the proposed fuzzy logic control scheme is effective to prevent a tractor semitrailer from falling into jackknife and trailer oscillation in a wide range of road adhesion condition.

\section{Appendices}

\section{A. Description of Vehicle Physical Parameters}

$m_{1}, m_{1 s}:$ total mass, sprung mass of the tractor,

$m_{2}, m_{2 s}$ : total mass, sprung mass of the trailer,

$I_{z 1}, I_{x 1}$ : yaw moment of inertia, roll moment of inertia of the tractor,

$I_{z 2}, I_{x 2}$ : yaw moment of inertia, roll moment of inertia of the trailer,

$l_{1}, l_{2}$ : wheel base of the tractor, distance from the hitch point to the rear axle of the trailer,

$a_{1}, b_{1}$ : distance from the CG of the tractor to its front, rear axle,

$l_{p}$ : distance from the CG of the tractor to the hitch point,

$a_{2}, b_{2}$ : distance from the trailer CG to the hitch point and the rear axle of the trailer,

$t_{w 1}, t_{w 2}, t_{w 3}$ : track width of tractor front axle, tractor rear axle, and trailer rear axle,

$h_{c 1}, h_{c 2}$ : height of the tractor CG, height of the trailer CG,

$h_{s 1}, h_{s 2}$ : distance from the tractor CG to its roll axis, distance from the trailer CG to its roll axis,

$h_{f 1}, h_{r 1}$ : height of front, rear roll centre of the tractor, $h_{f 2}, h_{r 2}$ : height of front, rear roll centre of the trailer,

$h_{p}$ : height of the hitch point,

$K_{h t}$ : coupling roll stiffness between the tractor and the trailer,

$K_{s 1 i}, K_{s 2 i}, K_{s 3 i}$ : suspension stiff coefficients of tractor front axle, tractor rear axle, and trailer rear axle, $i=$ 1,2 ,

$D_{s 1}, D_{s 2}, D_{s 3}$ : suspension damping coefficients of tractor front axle, tractor rear axle, and trailer rear axle,

$R_{w i}, I_{w i}, \omega_{w i}, T_{b i}$ : wheel rolling radius, rotary moment of inertia, wheel angular velocity, and wheel brake torque of the $i$ th wheel, $i=1 \sim 6$,

$\alpha_{i}, \lambda_{i}$ : side slip angle, longitudinal slip ratio of the $i$ th wheel, $i=1 \sim 6$,

$C_{y 1}, C_{y_{2}}, C_{y 3}$ : cornering stiffness of tractor front axle, cornering stiffness of tractor rear axle, and cornering stiffness of trailer rear axle for linear vehicle model,

$C_{x f}, C_{x r}, C_{x t}$ : longitudinal stiffness of tractor front axle, longitudinal stiffness of tractor rear axle, and longitudinal stiffness of trailer rear axle in Dugoff tyre model,

$C_{y f}, C_{y r}, C_{y t}$ : lateral stiffness of tractor front axle, lateral stiffness of tractor rear axle, and lateral stiffness of trailer rear axle in Dugoff tyre model,

$F_{x i}, F_{y i}, F_{z i}$ : longitudinal, lateral, and normal force of the $i$ th wheel, $i=1 \sim 6$,

$F_{h x}$ : longitudinal interaction force between the tractor and the trailer,

$F_{h y}$ : lateral interaction force between the tractor and the trailer,

$\gamma_{1}, \phi_{1}$ : yaw rate, roll angle of the tractor,

$v_{x 1}$ : longitudinal velocity of the tractor,

$v_{y 1}$ : lateral velocity of the tractor,

$\gamma_{2}, \phi_{2}$ : yaw rate, roll angle of the trailer,

$v_{x 2}, v_{y 2}$ : longitudinal velocity, lateral velocity of the trailer,

g: gravity acceleration,

$\theta$ : hitch angle between the tractor and the trailer.

\section{B. Vehicle Physical Parameters Used in Simulation}

$$
\begin{aligned}
& m_{1}: 8444 \mathrm{~kg}, \\
& m_{2}: 23472 \mathrm{~kg}, \\
& I_{z 1}: 64112 \mathrm{~kg} \cdot \mathrm{m}^{2}, \\
& I_{z 2}: 623150 \mathrm{~kg} \cdot \mathrm{m}^{2}, \\
& l_{1}: 4.81 \mathrm{~m}, \\
& a_{1}: 2.21 \mathrm{~m},
\end{aligned}
$$



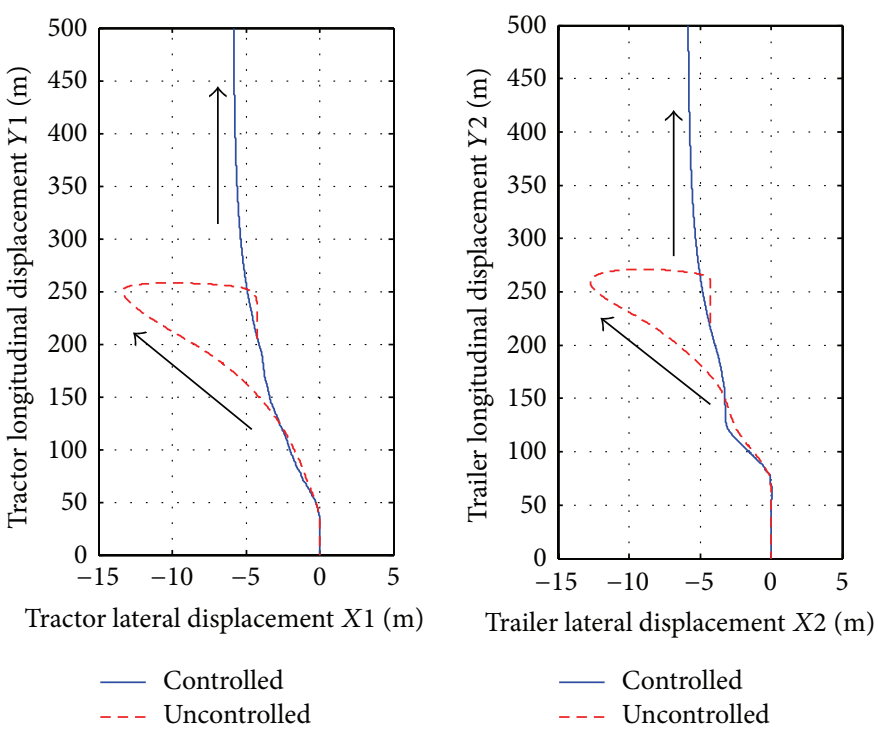

Controlled

- - - Uncontrolled

FIGURE 20: Global trajectory and comparison for the single lane change maneuver on a dry road. Arrows in the figure represent the vehicle running direction.
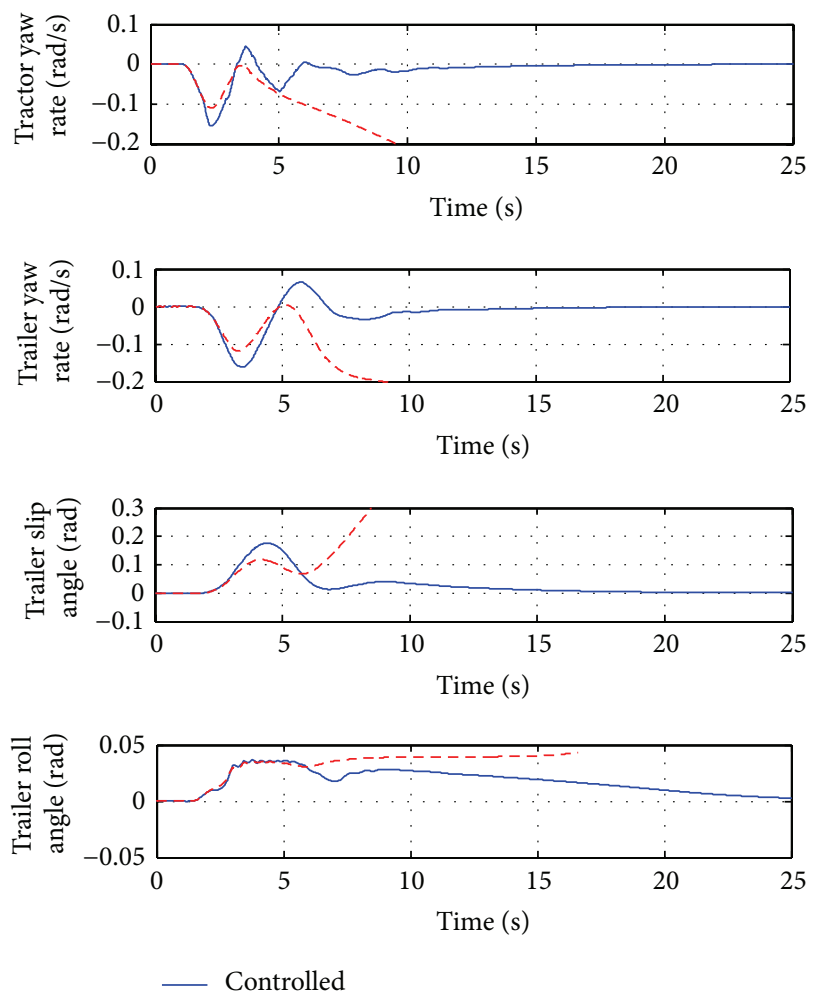

- - Uncontrolled

FIGURE 21: State and comparison for the single lane change maneuver on a slippery road.

$$
\begin{aligned}
& t_{w 1}: 1.93 \mathrm{~m}, \\
& t_{w 3}: 1.84 \mathrm{~m}, \\
& h_{s 2}: 1.40 \mathrm{~m}, \\
& h_{c 2}: 2.03 \mathrm{~m}, \\
& h_{r 1}: 0.82 \mathrm{~m},
\end{aligned}
$$
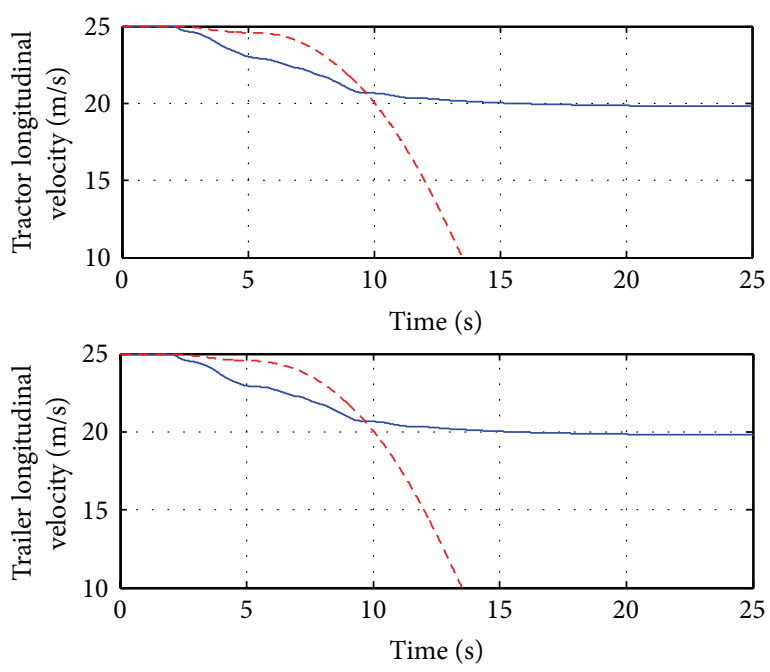

- Controlled

- - - Uncontrolled

FIGURE 22: Longitudinal velocity for the single lane change maneuver on a slippery road.

$$
\begin{aligned}
& h_{p}: 1.27 \mathrm{~m}, \\
& h_{r 2}: 0.80 \mathrm{~m}, \\
& K_{s 12}: 2.40 \times 10^{10} \mathrm{~N} / \mathrm{rad}, \\
& K_{s 21}: 4.32 \times 10^{4} \mathrm{~N} / \mathrm{rad}, \\
& K_{s 22}: 7.20 \times 10^{10} \mathrm{~N} / \mathrm{rad}, \\
& K_{s 32}: 9.60 \times 10^{11} \mathrm{~N} / \mathrm{rad}, \\
& C_{x f}: 6.00 \times 10^{4} \mathrm{~N} / \text { unit slip, } \\
& C_{x r}: 1.10 \times 10^{5} \mathrm{~N} / \text { unit slip, } \\
& C_{x t}: 1.40 \times 10^{5} \mathrm{~N} / \text { unit slip, }
\end{aligned}
$$




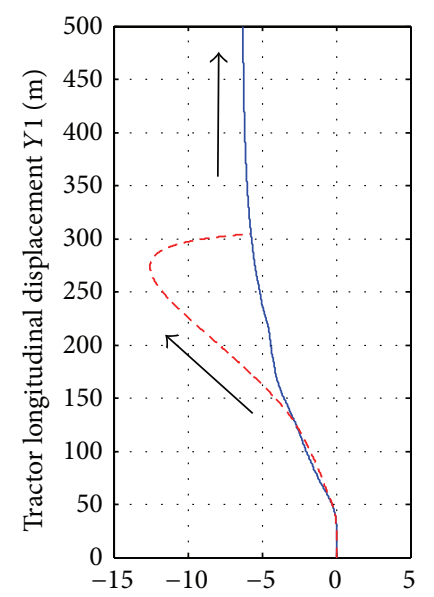

Tractor lateral displacement $X 1(\mathrm{~m})$

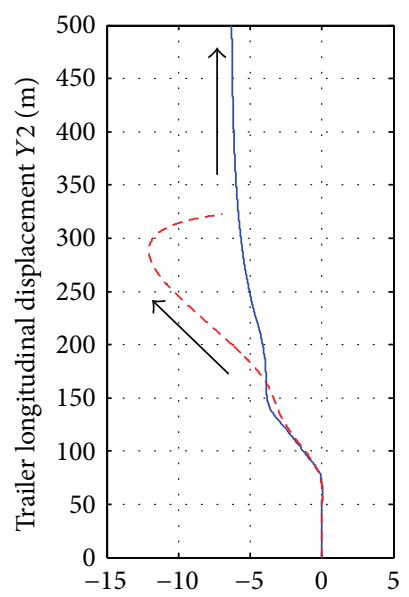

Trailer lateral displacement $X 2(\mathrm{~m})$

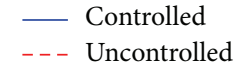

FIGURE 23: Global trajectory and comparison for the single lane change maneuver on a slippery road. Arrows in the figure represent the vehicle running direction.

$$
\begin{aligned}
& C_{y 1}: 1.40 \times 10^{5} \mathrm{~N} / \mathrm{rad}, \\
& C_{y 3}: 3.90 \times 10^{5} \mathrm{~N} / \mathrm{rad}, \\
& R_{w 1}: 0.52 \mathrm{~m}, \\
& R_{w 3}: 0.52 \mathrm{~m}, \\
& I_{w 2}: 130 \mathrm{~kg} \cdot \mathrm{m}^{2}, \\
& g: 9.81 \mathrm{~m} / \mathrm{s}^{2}, \\
& m_{1 s}: 5820 \mathrm{~kg}, \\
& m_{2 s}: 21640 \mathrm{~kg}, \\
& I_{x 1}: 10347 \mathrm{~kg} \cdot \mathrm{m}^{2}, \\
& I_{x 2}: 58270 \mathrm{~kg} \cdot \mathrm{m}^{2}, \\
& l_{p}: 2.52 \mathrm{~m}, \\
& l_{2}: 11.82 \mathrm{~m}, \\
& t_{w 2}: 1.84 \mathrm{~m}, \\
& h_{s 1}: 0.40 \mathrm{~m}, \\
& h_{c 1}: 1.18 \mathrm{~m}, \\
& h_{f 1}: 0.75 \mathrm{~m}, \\
& h_{f 2}: 0.60 \mathrm{~m}, \\
& K_{h t}: 6.90 \times 10^{6} \mathrm{Nm} / \mathrm{rad}, \\
& K_{s 11}: 1.60 \times 10^{4} \mathrm{~N} / \mathrm{rad}, \\
& D_{s 1}: 8.50 \times 10^{3} \mathrm{~N} / \mathrm{rad} \cdot \mathrm{s}^{-1}, \\
& D_{s 2}: 8.50 \times 10^{3} \mathrm{~N} / \mathrm{rad} \cdot \mathrm{s}^{-1}, \\
& K_{s 31}: 7.68 \times 10^{4} \mathrm{~N} / \mathrm{rad}, \\
& D_{s 3}: 8.50 \times 10^{3} \mathrm{~N} / \mathrm{rad} \cdot \mathrm{s}^{-1}, \\
& C_{y f}: 4.00 \times 10^{4} \mathrm{~N} / \mathrm{rad}, \\
& C_{y r}: 8.00 \times 10^{4} \mathrm{~N} / \mathrm{rad}, \\
& C_{y t}: 1.00 \times 10^{5} \mathrm{~N} / \mathrm{rad},
\end{aligned}
$$

$$
\begin{aligned}
& C_{y 2}: 3.90 \times 10^{5} \mathrm{~N} / \mathrm{rad}, \\
& \varepsilon_{r}: 0.015, \\
& R_{w 2}: 0.52 \mathrm{~m}, \\
& I_{w 1}: 40.8 \mathrm{~kg} \cdot \mathrm{m}^{2}, \\
& I_{w 3}: 130 \mathrm{~kg} \cdot \mathrm{m}^{2} .
\end{aligned}
$$

\section{Conflict of Interests}

The authors declare that there is no conflict of interests regarding the publication of this paper.

\section{Acknowledgments}

This project was supported by the National Natural Science Foundation of China (NSFC, 51465023). The authors are greatly appreciated for the financial support.

\section{References}

[1] J. Woodrooffe, D. F. Blower, T. J. Gordon et al., "Safety benefits of stability control systems for tractor-semitrailers," Final Report, National Highway Traffic Safety Administration, 2009.

[2] E. F. Kurtz and R. J. Anderson, "Handling characteristics of car-trailer systems: a state-of-the-art survey," Vehicle System Dynamics, vol. 6, no. 4, pp. 217-243, 1977.

[3] F. Vlk, "Lateral dynamics of commercial vehicle combinations a literature survey," Vehicle System Dynamics, vol. 11, no. 5-6, pp. 305-324, 1982.

[4] R. W. Goldman, M. El-Gindy, and B. T. Kulakowski, "Rollover dynamics of road vehicles: literature survey," Heavy Vehicle Systems, vol. 8, no. 2, pp. 103-141, 2001.

[5] M. A. E. Elhemly and M. A. G. Fayed, "Simulation of tractor semitrailer manoeuvre at high speed using MATLAB/ SIMULINK," International Journal of Heavy Vehicle Systems, vol. 18, no. 4, pp. 341-358, 2011. 
[6] Y. He, A. Khajepour, J. McPhee, and X. Wang, "Dynamic modelling and stability analysis of articulated frame steer vehicles," International Journal of Heavy Vehicle Systems, vol. 12, no. 1, pp. 28-59, 2005.

[7] H. Aleksander, F. Daniel, and C. Hsien, "Stability and control considerations of vehicle-trailer combination," SAE Paper 200801-1228, SAE International, 2008.

[8] X. Yang and J. Xiong, "Nonlinear yaw dynamics analysis and control for the tractor-semitrailer vehicle," International Journal of Heavy Vehicle Systems, vol. 20, no. 3, pp. 253-288, 2013.

[9] A. M. Sharaf, "Directional stability of tractor-semitrailers versus truck-full trailers," International Journal of Heavy Vehicle Systems, vol. 20, no. 1, pp. 61-75, 2013.

[10] J. Wideberg and E. Dahlberg, "Effect of the fifth-wheel placement on the stability of articulated vehicles," International Journal of Heavy Vehicle Systems, vol. 20, no. 2, pp. 144-156, 2013.

[11] P. Lugner, M. Plochl, and A. Riepl, "Investigation of passenger car-trailer dynamics controlled by additional braking of the trailer," in Proceedings of the International Symposium on Advanced Vehicle Control (AVEC '96), pp. 763-778, Aachen University of Technology, Aachen, Germany, 1996.

[12] M. A. Alonso Fernandez and R. S. Sharp, "Caravan active braking system-effective stabilisation of snaking of combination vehicles," SAE Technical Paper 2001-01-3188, 2001.

[13] J. M. Williams and F. W. Mohn, “Trailer stabilization through active braking of the towing vehicle," SAE Technical Paper 2004-01-1069, 2004.

[14] V. Zanten, "Bosch ESP systems: 5 years of experience," SAE Technical Paper 2000-01-1633, 2000.

[15] B. L. Boada, M. J. L. Boada, and V. Díaz, "Fuzzy-logic applied to yaw moment control for vehicle stability," Vehicle System Dynamics, vol. 43, no. 10, pp. 753-770, 2005.

[16] M. Sahin and Y. S. Ünlüsoy, "Design and simulation of an ABS for an integrated active safety system for road vehicles," International Journal of Vehicle Design, vol. 52, no. 1-4, pp. 64-81, 2010.

[17] G. Tekin and Y. S. Ünlüsoy, "Design and simulation of an integrated active yaw control system for road vehicles," International Journal of Vehicle Design, vol. 52, no. 1-4, pp. 5-19, 2010.

[18] SAE International, Manual on Design and Application of Leaf Springs, SAE HS J788, SAE International, Warrendale, Pa, USA, 1980.

[19] H. Dugoff, P. S. Francher, and L. Segel, "An analysis of tire traction properties and their influence on vehicle dynamic performance," SAE Technical Paper 700377, SAE International, 1970.

[20] W. Deng, Y. H. Lee, and M. Tian, "An integrated chassis control for vehicle-trailer stability and handling performance," SAE Technical Paper 2004-01-2046, 2004.

[21] K. Koibuchi, M. Yamaoto, Y. Fukada et al., "Vehicle stability control in limit cornering by active brake," SAE Technical Paper 960487, 1996.

[22] C. Chen and M. Tomizuka, "Lateral control of commercial heavy vehicles," Vehicle System Dynamics, vol. 33, no. 6, pp. 391420, 2000. 


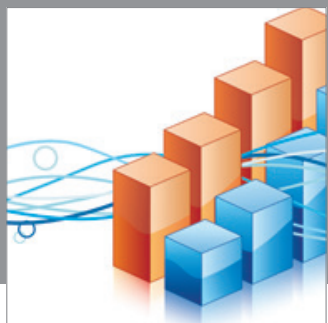

Advances in

Operations Research

mansans

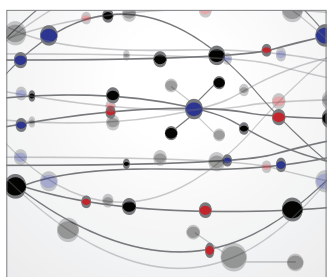

The Scientific World Journal
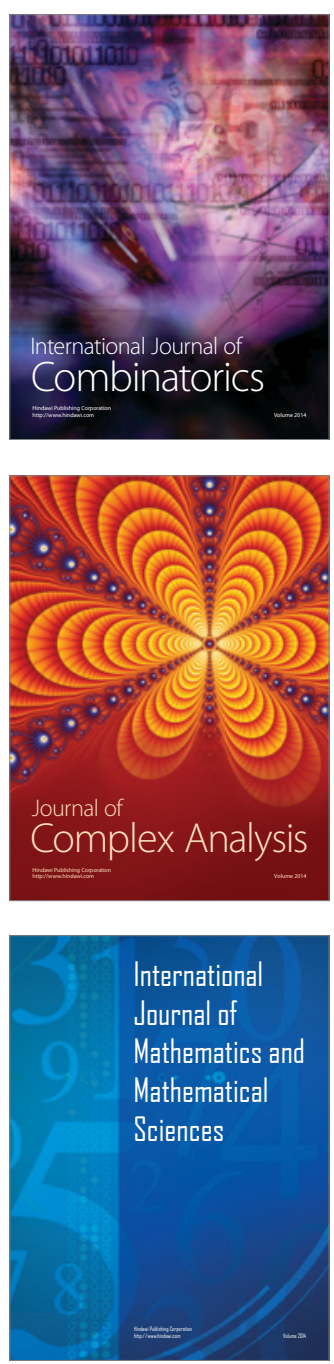
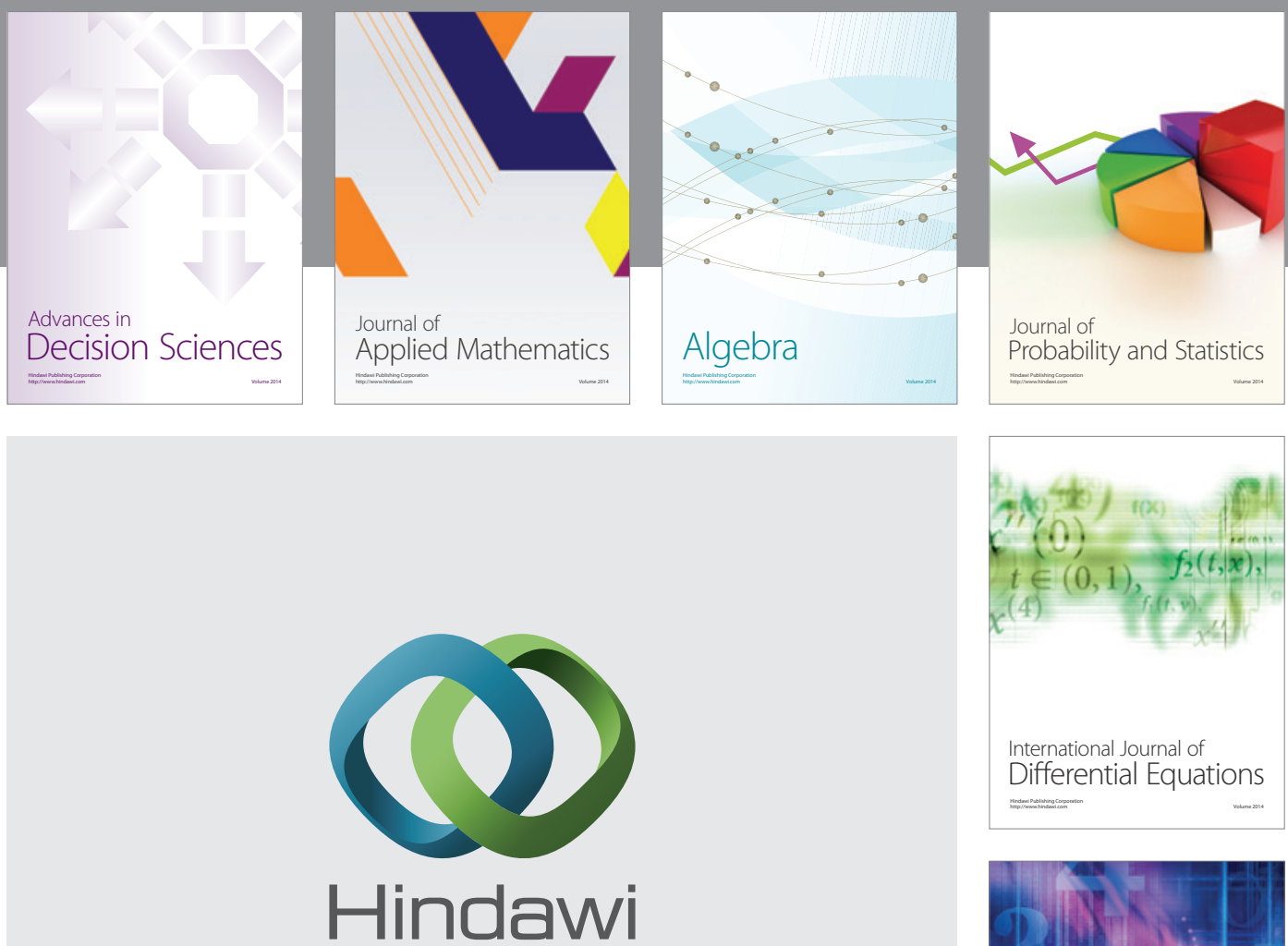

Submit your manuscripts at http://www.hindawi.com
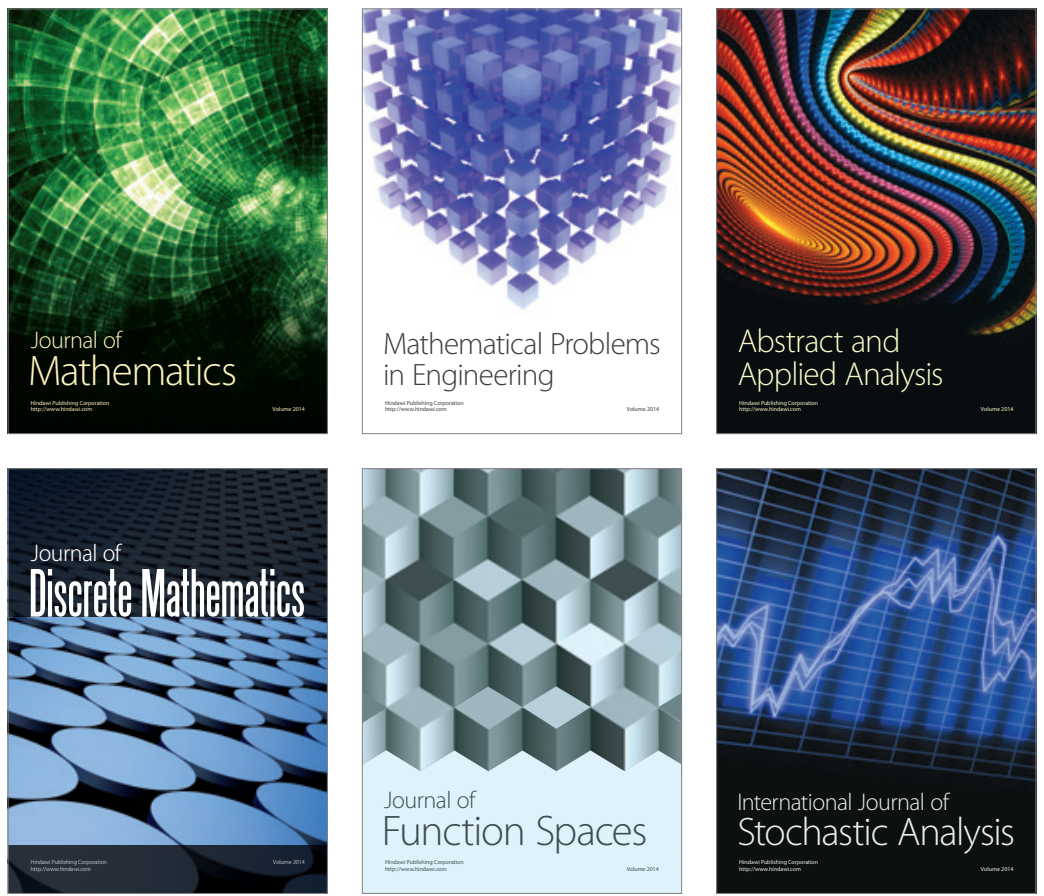

Journal of

Function Spaces

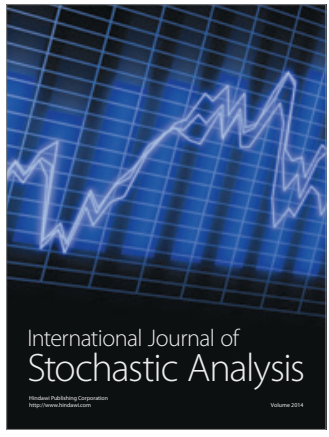

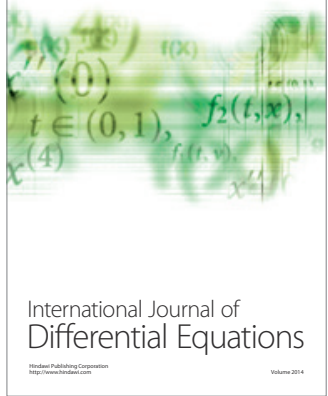
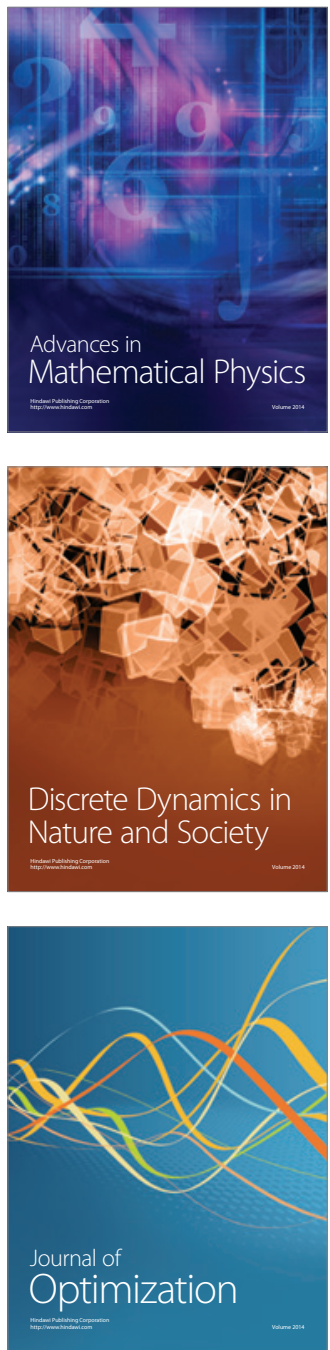